\title{
Teacher and Student Interactions in the First Year of University
}

\author{
Claudia Andrea Rivera Munoz \\ http://orcid.org/0000-0002-7976-1026
}

Submitted in total fulfilment of the degree of Master of Education (Research)

July 2017

Melbourne Graduate School of Education;

University of Melbourne 


\section{Table of Contents}

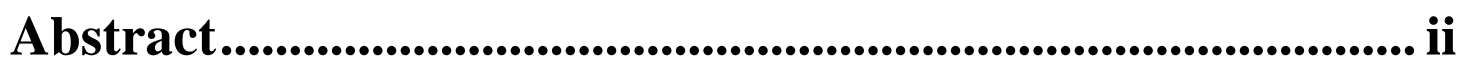

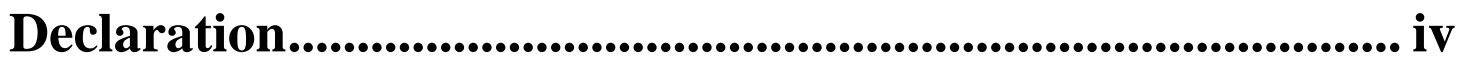

Acknowledgments .................................................................................... $\mathrm{V}$

Chapter 1 Introduction...................................................................... 1

$1.1 \quad$ Context of the Study ……………………………………….......

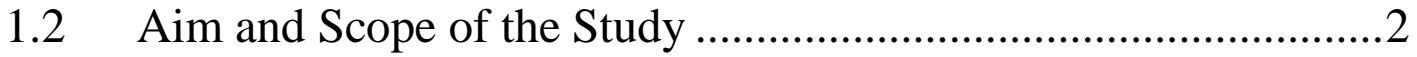

1.3 Significance..........................................................................

1.4 Overview .............................................................................

Chapter 2 Literature Review .......................................................... 4

2.1 Benefits of Teacher-Student Interactions in Higher Education....4

2.2 Teacher-Student Interactions: Types, Quality and Determinants.7

2.3 Teacher-Student Interactions in the First Year............................12

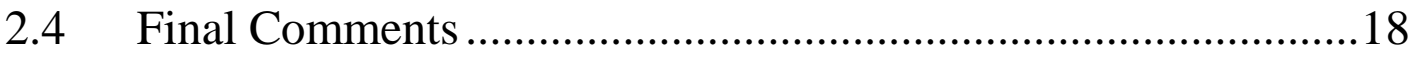

Chapter 3 Methodology .................................................................. 21

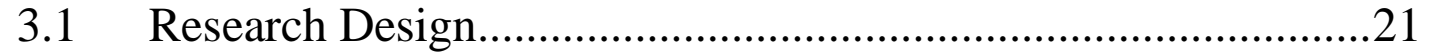

3.2 Data Collection Methods ......................................................24

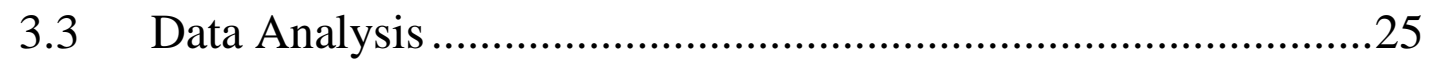

3.4 Quality of the Study: Rigour and Trustworthiness .....................29

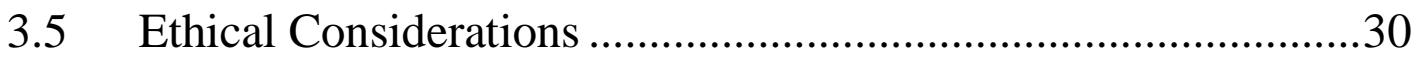

Chapter 4 Findings............................................................................ 31

4.1 Teacher-Student Interactions: Expectations and Experiences....31

4.2 Benefits of Positive Teacher-Student Interactions ......................46

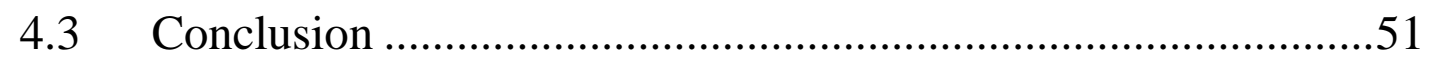

Chapter 5 Discussion and Conclusions...................................... 52 
5.1 Teacher-Student Interactions in the First Year..........................52

5.2 Academic Benefits of Positive Teacher-Student Interactions ....56

5.3 Limitations and Suggestions for Further Research.....................60

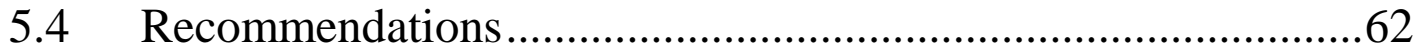

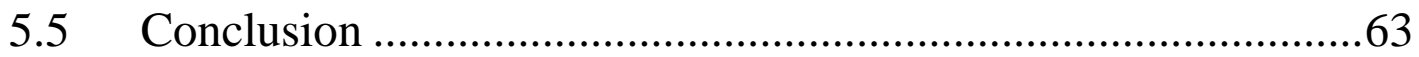

References ...................................................................................6 64

Appendices ........................................................................... 73

Appendix 1: Questions of Semi-Structured Interviews ...........................74

Appendix 2: Study's Plain Language Statement .....................................75

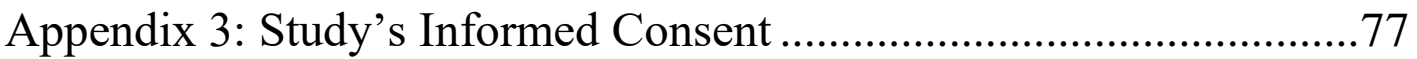

Appendix 4: Socio-Demographic Questionnaire .....................................78

Appendix 5: Example of Coding, Subtopics and Topics ........................79

Appendix 6: Ethics Letter of Approval .................................................8 


\section{List of Tables and Figures}

\section{Tables}

Table 2.1 Questions of three Australian surveys to gauge teacher-student interactions .........13

Table 3.1 Participants' socio-demographic and educational characteristics ..........................23

Table 3.2 Coding convention of participants in this research..............................................26

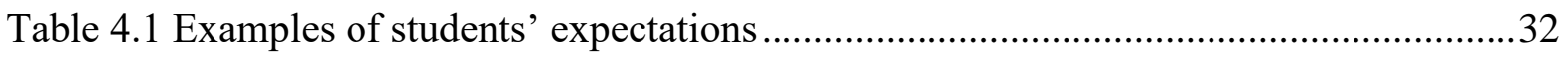

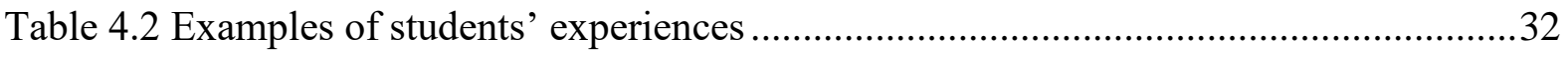

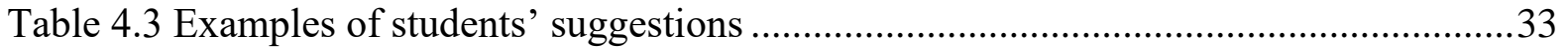

Table 4.4 Categories and types of teacher-student interactions...........................................35

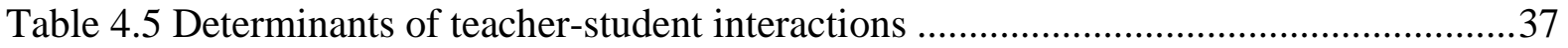

Table 4.6 Student factors and their influences on teacher-student interactions.......................38

Table 4.7 Institutional factors and their influences on teacher-student interactions................39

Table 4.8 Peers factors and their influences on teacher-student interactions .........................40

Table 4.9 Teacher factors that facilitated teacher-student interactions.................................42

Table 4.10 Teacher factors that hindered teacher-student interactions ..................................42

Table 4.11 Characteristics of positive and helpful teacher-student interactions ....................44

Table 4.12 Characteristics of negative and unhelpful teacher-student interactions................45

Table 4.13 Influences of teacher-student interactions on motivation and engagement ...........46

Table 4.14 Influences of teacher-student interactions on learning ......................................48

Table 4.15 Sense of belonging to the university and social/communication skills ................50

\section{Figures}

Figure 2.1 Typology of interactions outside classrooms in residential colleges (Based on the

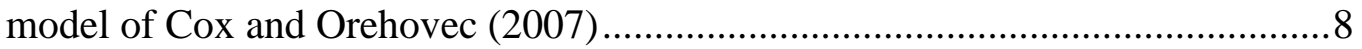

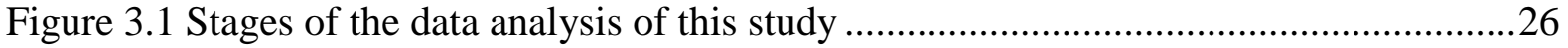

Figure 3.2 Coding frame of two positive characteristics of the quality of interactions ...........28

Figure 4.1 Preliminary diagram of benefits of positive teacher-student interactions ..............49

Figure 5.1 Diagram integrative of academic benefits of teacher-student interactions ............60 


\begin{abstract}
The first year of university is often considered challenging and difficult for students who are adjusting to different academic and social demands. In this context, teacher-student interactions play a key role in encouraging students' motivation, engagement, learning, sense of belonging to the university and academic persistence (Kuh, Jillian, Schuh, \& Whitt, 2010; Pascarella \& Terenzini, 1991; Ryan \& Deci, 2000; Tinto, 1993). A vast body of research suggests that regular and high-quality interactions between teachers and students benefit academic performance and social integration of students (Kuh et al. 2010; Pascarella \& Terenzini, 1991). However, few studies have examined in depth the nature of the interactions that students establish with their teachers in the first year in the Australian context.

This qualitative study examined teacher and student interactions in the first year of university from students' perspectives in one large public Australian university. This study asked:

a) What are the expectations and experiences of undergraduate students regarding the interactions with their tutors and lecturers in the first year of university?

b) How have these interactions influenced students' motivation, engagement, learning, and sense of belonging to their university?

Twenty-one undergraduate students enrolled in the first and second year of a bachelor degree participated in semi-structured interviews. In these interviews, participants talked about their expectations and experiences of interactions with their teachers in the first year and the influences of these interactions on their studies. All interviews were transcribed and thematically analysed to identify common themes in students' experiences (Boyatzis, 1998; Braun \& Clarke, 2006; Schreier, 2013).

The findings showed that students' expectations and experiences of the interactions differed by teacher's role. Participants reported having limited interactions with lecturers coinciding with their expectations. On the other hand, the interactions with tutors were recurrent but not as frequent as students expected. Regarding the types of interactions, the majority had an academic purpose and occurred inside classrooms. The quality of the interactions was assessed considering affective and academic dimensions. Participants reported that the majority of their interactions were positive, helpful, and influenced their motivation, engagement and learning. However, developing a sense of belonging to the university was not related to the interactions with teachers. In brief, this study highlights the
\end{abstract}


role that academic staff plays in fostering close, caring and supportive interactions with first year students to encourage their academic and social adjustment to the university. 


\section{Declaration}

This is to certify that:

i. The thesis comprises only my original work towards the Master except where indicated,

ii. Due acknowledgement had been made in text to all other material use,

iii. The thesis is (26124) words in length including tables, references and appendices as approved by the Research Higher Degrees Committee. 


\section{Acknowledgments}

The completion of the Master's thesis was a significant achievement and I would like to acknowledge the support of my supervisors, Dr Chi Baik and Dr Jason Lodge who provided prompt, sympathetic and valuable advice along the process of this research. Also, I would like to thank my family, particularly my parents who have always encouraged me to achieve my goals and grow personally and professionally. Finally, I would like to express my gratitude to the University of Melbourne and the Graduate School of Education for funding my Master's studies through the Melbourne Research Scholarship. 


\section{Chapter 1 Introduction}

\subsection{Context of the Study}

The first year of university can be challenging and complicated for most students who adapt to new academic and social contexts (Christie et al., 2016; Gibney et al., 2011). In this period of transition from high school, teaching staff plays a vital role in supporting the adaptation of new students helping them to succeed both academically and personally. Interactions between teachers and students have been widely recognised as a central factor for improving learning, engagement and retention of students (Astin, 1999; Pascarella \& Terenzini, 1991; Tinto, 1993). Faculty and student interactions often refer to the interactions between academic staff and students that occur in and outside classrooms, and that vary in frequency, purpose, and quality (Cox \& Orehovec, 2007; Pascarella, 1980).

In Western countries, particularly in the USA and Australia, the majority of research on teacher and student interactions in higher education has been undertaken using large-scale surveys. These surveys are usually administered to first and last year undergraduate students of colleges and universities to evaluate their academic experience and engagement in the institutions. This broad body of research has focused on the frequency and main effects of the teacher-student interactions on students' academic variables including motivation, engagement and academic success (Astin, 1993; Kuh et al., 2010; Pascarella \& Terenzini, 1991). Evidence suggests that regular and high-quality teacher and student interactions encourage students' motivation, engagement, learning and sense of belonging to their institutions (Astin, 1993; Kuh et al., 2010; Pascarella \& Terenzini, 1991; Ryan \& Deci, 2000; Tinto, 1993).

However, recent findings of the first year experience in Australian institutions have reported that students present relatively low levels of engagement and sense of belonging to their institutions and limited interactions with their academic staff (Baik, Naylor, \& Arkoudis, 2015; Quality Indicators for Learning and Teaching (QILT), 2017a). In a context of an increasing and diverse number of students entering universities ${ }^{1}$, a lack of engagement and limited interactions with teachers could lead to students having difficulties in adjusting

${ }^{1}$ Massification of higher education refers to the increase in the students' enrolment quotes in institutions including students from different backgrounds and socioeconomic levels. This massification also have promoted a diversification in the offer of higher education institutions (Teichler, 1998). 
educationally and socially to universities that may influence not only students' learning and academic performance but also their mental health and well-being. In this context, it seems necessary that universities understand the nature and role that teacher-student interactions play in the first year to develop and implement interventions in this area and promote students' learning and sense of belonging to the university.

Regarding research on teacher-student interactions, few qualitative studies have been undertaken to comprehend in depth the students' experiences about interactions with their teachers and the reasons to explain the benefits reported by survey-based research (Hagenauer \& Volet, 2014). Particularly in the Australian context, there is limited evidence about the perceptions of students regarding the interactions with their tutors and lecturers in the first year of university.

\subsection{Aim and Scope of the Study}

This study examines teacher and student interactions in the first year of university from the perspective of undergraduate students at one large public Australian university. This research focuses on the interactions that occurred inside and outside classrooms between students and tutors and lecturers. Regarding interactions inside classrooms, this study evaluates two academic settings: tutorials and lectures. Accordingly, this study has two research questions. The first one is to investigate undergraduate students' expectations and experiences of their interactions with tutors and lecturers during their first year of university. The second research question seeks to analyse the students' perceptions of the effects of the interactions on motivation, engagement, learning, and sense of belonging to the university.

\subsection{Significance}

As discussed above, diverse Australian studies have reported concerning results of the first year students' educational experiences in the universities, and there is insufficient qualitative evidence on the nature of the interactions that students establish with their teachers. Therefore, this study contributed to the understanding of teacher-student interactions in the Australian context from students' perspectives. This research provided comprehension of the effects that interactions had on motivation, engagement, learning, and sense of belonging to the university. On a practical level, the findings of this study can inform universities subject coordinators and academic staff to develop interventions in the 
first year to promote good teaching and learning practices including developing positive teacher-student interactions in and outside classrooms.

\subsection{Overview}

This thesis consists of five chapters. The next two chapters situate the current study regarding the literature on teacher and student interactions and the research design undertaken. Specifically, Chapter 2 discusses present and relevant evidence of the benefits of teacher and student interactions in higher education, types and quality of interactions, and empirical studies of teacher-student interactions. Chapter 3 explains the methodology of this study including research design, participants' recruitment, data collection and data analysis. At the end of this thesis, appendices complement information presented in Chapter 3.

The last two chapters analyse findings, discussion and implications for the first year of university. Having clarified the context and procedures taken in this research, Chapter 4 reviews the results of this study, particularly, participants' expectations and experiences of the interactions, typology and quality of interactions and benefits of positive teacher and student interactions. Finally, Chapter 5 discusses the implications of the main findings considering evidence on teacher and student interactions. This last chapter also reports the limitations of this study and suggestions for further research finishing with recommendations for higher education coordinators and academic staff. 


\section{Chapter 2 Literature Review}

This literature review analyses evidence of faculty and student interactions in higher education showing its contributions and gaps. This chapter has four sections. The first section discusses theoretical and research evidence about the benefits of teacher and student interactions in higher education, particularly, motivation, engagement, learning, retention, and sense of belonging to the university. The second section analyses evidence about types of interactions, characteristics of positive and negative interactions, and factors that influence teacher and student interactions. The third section examines empirical studies on undergraduate students' experiences regarding frequency and quality of teacher and student interactions, especially in the first year. The last section concludes with the most important points from the literature review and research. Finally, it is argued how this research would contribute to the understanding of teacher and student interactions in the first year in the Australian context.

\subsection{Benefits of Teacher-Student Interactions in Higher Education}

A significant effect of positive teacher-student interactions is their influence on motivation. According to Ryan and Deci (2000), intrinsic motivation is "the tendency to learn, explore and seek challenges" (p.70) driven by internal goals. In the educational context, Ryan and Deci (2000) postulate that feeling intrinsically motivated facilitates learning and academic performance. The development and maintenance of the intrinsic motivation require a supportive environment that encourages feelings of competence, autonomy and relatedness with others (Ryan \& Deci, 2000). Students are intrinsically motivated when they have regular experiences of autonomy and competence in their academic activities and feel connected to others, particularly teachers and peers (Ryan \& Deci, 2000). Supporting this argument, some studies report that frequent and positive interactions with teachers increase students' motivation (Komarraju, Musulkin, \& Bhattacharya, 2010; Rugutt \& Chemosit, 2009).

Moreover, engagement or involvement is another element associated with positive and regular interactions between students and teachers. According to Astin (1999), student involvement is "the amount of physical and psychological energy that the student devotes to the academic experience" (p.518), and it is directly related to student learning and personal 
development. Astin (1999) points out that students who are engaged in their learning, spend time on academic activities, interact with teachers and peers, and are more likely to improve their academic performance and personal growth. Research on students' engagement has concluded that teacher-student interactions are the most significant factor related to satisfaction with college and academic performance (Astin, 1999; Groves, Sellars, Smith, \& Barber, 2015). In fact, some studies show that students who perceive their teachers as available and interested in their learning are more likely to be engaged, motivated and satisfied with their educational experience (Groves et al., 2015; Richardson \& Radloff, 2014). Students highly involved in their classes tend to challenge themselves to meet their educational goals, and seek help from teachers influencing their learning outcomes in a particular subject (Kim \& Lundberg, 2016; Kim \& Sax, 2014; Pascarella, 1985).

Faculty-student interactions have also been associated with the improvement of students' cognitive skills and learning outcomes (Pascarella, 1985). According to Pascarella (1985), the faculty is one of the main agents of socialisation in higher education influencing the learning outcomes of students through the interactions with them. The types of interactions that students and teachers establish in the first year determine their effects on learning. In fact, Kuh et al. (2010) and Pascarella (1985) have indicated that interactions with academic and intellectual purposes are the most significant for learning outcomes. Numerous studies and meta-analysis have concluded that the frequency of interactions with teachers in and out of classrooms influence positively students' academic achievement (Delaney, 2008; Kuh \& Hu, 2001; Kuh et al., 2010; Lundberg, 2014; Pascarella \& Terenzini, 1991). Also, positive interactions with staff improve the development of students' cognitive skills (Kim \& Lundberg, 2016; Lyken-Segoseb, 2015), educational aspirations and values (Cox \& Orehovec, 2007; Pascarella, 1980), and academic self-concept and self-challenge (Kim \& Sax, 2014).

Additionally, teacher-student interactions play a fundamental role in students' decision to continue their studies at a particular institution. Tinto (1993) indicates that frequent contact between students and academic staff outside classrooms is a predictor of retention and facilitates the academic and social integration of students in their institutions. For example, Turner and Thompson (2014) interviewed a group of students who left their studies and another group that continued through the second year at an American university. $50 \%$ of both groups reported not having frequent and helpful teacher-student interactions and $80 \%$ of current students and $50 \%$ of non-returning first year students mentioned a lack of academic support. The authors suggest that A common topic between both groups of students 
was that recurrent and positive interactions between students and teachers could influence students' academic persistence in the institutions. Similarly, Hixenbaugh, Dewart, and Towell (2012) conclude that high-quality interactions with teachers improve the retention of first year students and their sense of belonging to their institution.

Students' academic persistence has also been associated with the development of a sense of belonging to the institutions. Feelings of belonging or connectedness to their institutions have been defined from psychological and social perspectives. Regarding its psychological components, the definition has focused on individuals' feelings, attitudes and motivations towards a particular institution (Hurtado \& Carter, 1997). Other authors have emphasised the social components of the development of a sense of belonging to an institution (Lizzio, 2006; Tinto, 1993).

In Tinto's theory of retention, he indicates that one factor influencing students' persistence in college is how well students integrate into social and academic environments within a particular institution (Tinto, 1993). Social integration consists of having interactions and relationships with peers and teachers, and academic integration is related to affiliation and identification to the values and expectations of a particular faculty or institution (Lizzio, 2006; Tinto, 1993). Some studies on higher education have suggested that frequent and highquality interactions with academic staff contribute to students' academic adjustment (Sevinç \& Gizir, 2014) and social integration in higher education institutions (Hausmann, Schofield, \& Woods, 2007). This is even more relevant for students from different cultural and socieconomical backgrounds. Wirt \& Jaeger (2014) conclude that interactions between students and staff play a key role in the persistence of students who assist to community colleges.

On the other hand, developing a sense of belonging to classrooms is related to teacherstudent interactions. Some researchers suggest that positive interactions with teachers encouraged students to feel part of their classes (Freeman, Anderman, \& Jensen, 2007; Wilson et al., 2015; Zumbrunn, McKim, Buhs, \& Hawley, 2014). The sense of belonging to classes has been associated with teachers who promote a supportive environment in classrooms that encourage caring and respectful interactions among students and with teachers (Freeman et al., 2007). Many studies have reported that developing feelings of belonging and connection to classes facilitate students' engagement and motivation with the content and academic activities (Freeman et al., 2007; Wilson et al., 2015; Zumbrunn et al., 2014). In Australia, Morieson, Carlin, Clarke, Lukas, \& Wilson (2013) have emphasised that 
social interactions with peers benefit the sense of belonging to a school, particularly when they are promoted in and outside classes for the academic staff.

In conclusion, the research discussed in this section shed light on key academic benefits of teacher-student interactions in higher education. However, the majority of studies were undertaken in the American context that has particular curriculum emphasis and institutional characteristics that could differ with the qualities of Australian higher education.

\subsection{Teacher-Student Interactions: Types, Quality and Determinants}

The characteristics of teacher and student interactions have been widely studied in the school context where the concept has been defined, see for example the work of Robert Pianta (Pianta, 1999; Pianta, Hamre, \& Mintz, 2012). However, conceptualisations of teacher-student interactions in the school context differ from those between lecturers-tutors and students in higher education. According to Hagenauer \& Volet (2014), teacher-student interactions in the school context are between an adult and a child or adolescent whereas the interactions in higher education are between adults in which disciplinary and caring components could seem less relevant. Also, the teaching strategies and class sizes are different. While in schools, students learn in relatively reduced groups, in universities, especially large universities, class sizes of some lectures can be around 100 students. Therefore, the frequency and quality of teacher-student interactions in universities differ in comparison with schools.

In higher education, there are few conceptualisations of teacher-student interactions. One of them is from Ernest Pascarella who has extensively studied this topic, particularly interactions that occur outside classrooms. According to Pascarella (1980), teacher and student interactions outside classrooms have four dimensions: contextual or demographical, exposure, focus, and impact. The contextual element refers to the person (student or faculty member) who start the interaction. The exposure considers the frequency of teacher-student interactions in a given period. The focus consists of the purposes of the interactions such as academic and social. Finally, the impact refers to benefits obtained after the interaction and students' levels of satisfaction with it.

To date, there is a lack of precise descriptions of the types of interactions between students and faculty in higher education. One example of typology is the study of Cox and Orehovec (2007). Based on 20 students' perceptions, Cox and Orehovec (2007) elaborated a typology of interactions that occurred outside classrooms in a residential college of one large 
public American university. Although this typology consists of teacher-student interactions outside classrooms, it offers an organised description to understand the kinds of interactions occurring in higher education. Figure 2.1 shows the typology of interactions of Cox and Orehovec (2007) organised by the frequency reported by students, from the most frequent (disengagement) to the least frequent interaction (mentoring).

Figure 2.1 Typology of interactions outside classrooms in residential colleges (Based on the model of Cox and Orehovec (2007)

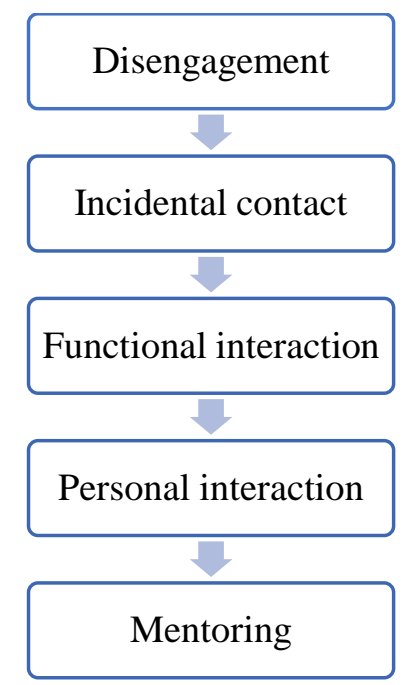

Cox and Orehovec (2007) found five types of interactions between teachers and students outside classrooms. Cox and Orehovec (2007) reported that the majority of students did not interact with their teachers outside classrooms calling the absence of interaction as disengagement. Incidental contact was the second most frequent interaction reported by students and "occurs when a student and a faculty member interact simply because they find themselves physically in the same place at the same time" (Cox, 2011, p.51). These interactions are often unintentional, and examples are greetings, smiling and other nonverbal communication between students and faculty.

The third type of interaction found was functional interactions that have a particular and academic related purpose (Cox \& Orehovec, 2007). For instance, when students seek teachers help and ask questions about content during office hours. The fourth type of interaction is called personal interactions. In these kinds of interactions students and academic staff actively seek the interaction, and they discuss personal interests, for example, teachers' research expertise/topics (Cox \& Orehovec, 2007). Finally, the least frequent type 
of interaction but the highest level of quality is mentoring. This type of interaction occurs when students and teachers develop a relationship which they interact for functional and personal purposes; for example, interactions when teachers give students emotional and academic support (Cox \& Orehovec, 2007). In mentoring interactions, teaching staff usually becomes a role model for students (Cox \& Orehovec, 2007).

According to Cox and Orehovec (2007), all types of interactions, excluding disengagement, can have meaningful and positive consequences for students. Cox (2011) describes two characteristics of this typology, fluidity and development. Cox (2011) states that the types of interactions in the typology are fluid, in other words, two or more types of interactions can occur continuously on one occasion. For example, incidental interactions can become functional interactions if students and teachers also discuss academic issues. Additionally, Cox (2011) considers that this typology is developmental which means that mentoring type of interactions requires higher levels of quality teacher-student interactions than functional interactions.

Another framework related to teacher and student interactions is the "desk side manner" (Fleischman \& Imaz-Marial, 2015) oriented for teachers to help students in their transition to higher education, especially regarding their wellbeing and mental health. This framework consists of four components; show respect, critical listening, the four Bs and follow up (Fleischman \& Imaz-Marial, 2015). Staff should show respect to students maintaining eye contact, and thanking them for approaching and communicate. Critical listening refers to the ability of staff to listen emphatically and with attention to the students' inquiries helping them to their academic progress. The four Bs refers to be thorough encouraging students to ask good questions, and be clear communicating with students. Also, staff should be honest with students about assessments criteria and learning outcomes. Finally, staff should be firm with students about their academic responsibilities and commitment with their work for their academic success. Finally, teachers should follow up with students about how helpful and productive the help was (Fleischman \& Imaz-Marial, 2015).

Regarding the quality of teacher-student interactions, few studies have evaluated the characteristics of positive and negative interactions in higher education. Some authors consider that positive interactions between teachers and students are characterised by trust, respect, intimacy, care and support from academic staff (Cokley et al., 2004; Dobransky \& Frymier, 2004; Hagenauer \& Volet, 2014). On the other hand, negative interactions usually occur when teachers are distant and uninterested on students' academic and personal 
development having limited interactions with students (Cokley et al., 2004). When teachers show a lack of interest in students' learning, students usually felt less supported by their educational experience (Cokley et al., 2004). The extreme of negative interactions is having direct aggressiveness and arguments between teachers and students (Astin, 1993).

Moreover, some factors influence frequency, quality and consequences of teacher and student interactions, including students' characteristics, institutional factors and teachers and teaching factors (Pascarella, 1980). Some student factors that influence the type and frequency of interactions with teachers are age, attitudes towards learning, social relationships, personality orientations including being responsible and engaged, levels of preparedness and confidence, prior academic experiences and expectations of college (Pascarella, 1980; Tinto, 1993). For instance, being a senior student with high levels of preparedness, engagement and confidence in abilities is highly associated with maintaining interactions with faculty in and outside classrooms (Fassinger, 1995; Kuh et al., 2010; Lizzio, 2006).

Particular institutional factors have an effect on teacher-student interactions including institutional and classroom size, and faculty's professional interests, values and expectations (Astin, 1977; Pascarella, 1980). Classroom size is a widely studied factor. Several researchers have postulated that large classes impede the interactions not only with faculty but also with peers (Feldman, 1983; Tinto, 1993). Teachers in large classes also tend to offer limited possibilities for students' participation in classrooms diminishing the likelihood that students seek academic staff outside classrooms (Fassinger, 1995; Weaver \& Qi, 2005).

Peers also can influence students' decision to interact with teachers. Pascarella (1980) considers that peers play a fundamental role regarding the values and perceptions of the interactions with teachers. When peers value and seek to interact with academic staff, students are more likely to establish interactions with teachers. In classrooms, peers' approval or disapproval of the interactions influence students' participation. Fassinger (1995) and Weaver and Qi (2005) indicate that when students fear peers' disapproval are less likely to interact and participate in classes, for example answering questions. Weaver and Qi (2005) report that if students are unsure of abilities and knowledge tend to avoid the participation in classes for the fear of being seen as unintelligent in front of peers.

Additionally, teacher-student interactions research has identified some teachers' attitudes and behaviours that influence the frequency and quality of the interactions including teachers that show accessibility, responsiveness and interest to connect with students and developing trust (Jaasma \& Koper, 1999; Moore \& Masterson, 1996; Pascarella, 1980). 
Positive teachers' verbal and nonverbal communication in classrooms encourage students to interact with their teachers. Examples of verbal communication are expressing verbally the disposition to interact, offering offices hours appointments to students for asking specific questions and calling students by name (Jaasma \& Koper, 1999; Kuh et al., 2010; Moore \& Masterson, 1996). Examples of nonverbal communication are maintaining eye contact and smiling (Jaasma \& Koper, 1999; Moore \& Masterson, 1996). Students often interpret these behaviours as teachers' willingness and openness to interact in and outside classrooms.

Similarly, particular teaching strategies have an effect on the frequency of teacherstudent interactions in and outside classrooms. According to Wilson, Woods, and Gaff (1974), social-psychological accessibility refers to teachers' disposition, willingness and openness to interact with students in and outside classrooms. Wilson et al. (1974) consider that teachers' beliefs and attitudes towards the interactions are often implicit but some teaching strategies can demonstrate teachers' social-psychological accessibility. Examples of teaching strategies are encouraging classroom participation and implementing discussion activities of ideas related to the subject (Wilson et al., 1974). Another strategy is using evaluation methods that promote students' opinions and ideas related to current topics or social problems (Wilson et al., 1974). According to Wilson et al. (1974), these activities show that teachers are interested in hearing students' opinions and views, paying attention to them and accepting their perspectives within classrooms activities.

Some empirical studies have supported Wilson's et al. (1974) ideas. Cole (2007) and Cotten \& Wilson (2006) report that when students have limited participation in classes and perceive a lack of teachers' attention, they are less likely to interact with academic staff out of classrooms. These findings suggest that students' interpretation of teachers' signals in classes can influence the decision to interact with teachers. Teachers' behaviours and attitudes in classes become even relevant in the case of commuter students ${ }^{2}$, as the majority of students enrolled in Australian institutions, who mainly have contact with academic staff only in classrooms, especially in the first year (Tinto, 1993).

While the evidence analysed in this section show some relevant characteristics of teacher-student interactions, particularly regarding types and quality of interactions, the majority of the studies were conducted more than a decade ago. Considering that the higher education context has changed quickly in the last decades adjusting to new demands of

${ }^{2}$ The term "commuter students" refers to students who live outside the university and commute to campus. 
society, it may be possible that some findings and implications of the studies reviewed are now less applicable than 10 or 20 year ago.

\subsection{Teacher-Student Interactions in the First Year}

This section discusses empirical evidence about the frequency and quality of interactions between teachers and students, particularly in the first year, and it is organised in two sections. First, there is an analysis of evidence from large-scale surveys ${ }^{3}$. Then, findings from qualitative studies of students' experiences are examined. Finally, a brief conclusion synthesises the main results from the literature.

\subsubsection{Evidence of large-scale surveys.}

Teacher-student interactions in higher education have been widely studied for the last four decades, principally, using large-scale surveys. Most of these studies have focused on the frequency and quality of interactions outside classrooms and the main consequences of these interactions. For example, Kuh et al. (2010) evaluated the results of National Survey of Student Engagement (NSSE) of 20 higher education institutions that rated higher in student' engagement and graduation rates to determine the best practices of these institutions. Pascarella and Terenzini (1991) evaluated the effects of college from around 2,600 studies of 20 years of research considering some of the main large scales surveys in the USA, the NSSE.

Hurtado et al. (2011) using mixed methods methodology analysed the characteristics of 3,003 first year students who regularly interacted with their teachers from over 117 American institutions. Students answered the Freshman Survey and the Your First College Year survey about their experiences in the first year. The results reported that students who participated in extra-curricular activities with staff tended to interact more frequently with their teachers (Hurtado et al., 2011). Also, students that felt treated with respect during classes and perceived that their teachers were concerned about their learning were more likely to interact with teachers (Hurtado et al., 2011). Finally, two groups of students reported having regular interactions with teachers, students that presented high levels of engagement with their learning and those who were struggling academically (Hurtado et al., 2011). These results suggest that students who were more actively involved with their learning and

\footnotetext{
${ }^{3}$ The surveys reviewed consist of likert-type or multichoice questions with numerical scores.
} 
university tended to interact regularly with academic staff, especially when they felt respected in and out classrooms.

In Australia, there are three major surveys administered to first year students. One of them is the Australian Survey of Student Engagement (AUSSE) that evaluates the experience of undergraduate students for more than 30 Australian and New Zealand institutions (Australian Council for Educational Research (ACER), 2016). The second questionnaire is the Student Experience Survey (SES) administered to first and last year students and coordinated by the Australian Government Department of Education and Training (Quality Indicators for Learning and Teaching (QILT), n.d.). The third instrument is the First Year Experience Survey that is applied to first year students of eight Australian universities lead by the Centre for the Studies in Higher Education (MCSHE) at the University of Melbourne (Baik et al., 2015). These three instruments measure students' engagement with learning and satisfaction with their educational experience in the institutions. However, these surveys contain different items and descriptions to evaluate teacher and student interactions in the university. Table 2.1 shows the diversity of questions and focuses on each survey.

Table 2.1 Questions of three Australian surveys to gauge teacher-student interactions

\begin{tabular}{|c|c|c|c|}
\hline Instrument & $\begin{array}{l}\text { Institution } \\
\text { associated }\end{array}$ & Items & Questions \\
\hline $\begin{array}{l}\text { Australian Survey } \\
\text { of Student } \\
\text { Engagement } \\
\text { (AUSSE) }\end{array}$ & $\begin{array}{l}\text { Australian Council } \\
\text { for Educational } \\
\text { Research (ACER) }\end{array}$ & $\begin{array}{l}\text { Student-Faculty } \\
\text { Interaction }\end{array}$ & $\begin{array}{l}\text { In your experience at your institution } \\
\text { during the current academic year, } \\
\text { about how often have you done each } \\
\text { of the following? } \\
\text {-Used email or a forum to } \\
\text { communicate with teaching staff } \\
\text {-Discussed your grades or } \\
\text { assignments with teaching staff } \\
\text {-Talked about your career plans with } \\
\text { teaching staff or advisors } \\
\text { - Discussed ideas from your readings } \\
\text { or classes with teaching staff outside } \\
\text { class } \\
\text { - Received prompt written or oral } \\
\text { feedback from teachers/tutors on } \\
\text { your academic performance } \\
\text { - Worked harder than you thought } \\
\text { you could to meet a teacher's/tutor's } \\
\text { standards or expectations } \\
\text { - Worked with teaching staff on } \\
\text { activities other than coursework (e.g. } \\
\text { students, family members, co- } \\
\text { workers, etc.) (ACER, 2017a, p. 1) }\end{array}$ \\
\hline
\end{tabular}




\begin{tabular}{|c|c|c|c|}
\hline & & & $\begin{array}{l}\text { Which of these boxes best represent } \\
\text { the quality of your relationships with } \\
\text { people at your institution? } \\
\text {-Relationships with teaching staff } \\
1 \text { Unavailable, unhelpful, } \\
\text { unsympathetic } \\
7 \text { Available, helpful, sympathetic } \\
\text { (ACER, 2017a, p. 2) }\end{array}$ \\
\hline $\begin{array}{l}\text { Student Experience } \\
\text { Survey (SES) }\end{array}$ & $\begin{array}{l}\text { Australian } \\
\text { Government } \\
\text { Department of } \\
\text { Education and } \\
\text { Training }\end{array}$ & $\begin{array}{l}\text { Teaching } \\
\text { quality }\end{array}$ & $\begin{array}{l}\text { During 2014-2015, to what extent } \\
\text { have the lecturers, tutors and } \\
\text { demonstrators: } \\
\text { Engaged you actively in learning? } \\
\text { Demonstrated concern for student } \\
\text { learning? } \\
\text { Provided clear explanations on } \\
\text { coursework and assessment? } \\
\text { Stimulated you intellectually? } \\
\text { Commented on your work in ways } \\
\text { that help you learn? } \\
\text { Seemed helpful and approachable? } \\
\text { Set assessment tasks that challenge } \\
\text { you to learn? (QILT, n.d., para. 7) } \\
\text { "During 2014-2015, to what extent } \\
\text { have you found academic or learning } \\
\text { advisors to be: available? helpful?" } \\
\text { (QILT, n.d., para. 15) }\end{array}$ \\
\hline $\begin{array}{l}\text { First Year } \\
\text { Experience Survey } \\
\text { (FYES) }\end{array}$ & $\begin{array}{l}\text { Melbourne Centre for } \\
\text { the Studies in Higher } \\
\text { Education (MCSHE) }\end{array}$ & $\begin{array}{l}\text { Engagement } \\
\text { with academic } \\
\text { staff }\end{array}$ & $\begin{array}{l}\text { "I feel confident that at least one of } \\
\text { my teachers knows my name. } \\
\text { I regularly seek advice or help from } \\
\text { academic staff" (Baik et al., 2015, p. } \\
\text { 40) }\end{array}$ \\
\hline
\end{tabular}

As seen in Table 2.1, the majority of the items have a focus on academic activities including seeking feedback or advice outside classrooms, particularly in the Australian Survey of Student Engagement (AUSSE). The Student Experience Survey (SES) evaluates the benefits of teacher-student interactions for learning, especially, engagement and intellectual challenge. Finally, the First Year Experience Survey (FYES) gauges personal dimensions of the interactions that can influence students' satisfaction, for example, teachers' knowing the name of students.

Regarding academic aspects of the interactions, the findings from the AUSSE 2012 (sample size 1000 first-year and later-year students) show that less than $20 \%$ of first year students sought advice or discussed ideas with the teachers outside classes, $25 \%$ often discussed their grades with teachers, and $46 \%$ received prompt feedback from teachers (ACER, 2017b). In contrast, results of the FYES administered in 2014 (sample size 1739 first 
year students) indicate that the majority of first year students sought advice and help from their teaching staff ${ }^{4}$ (Baik et al., 2015). In fact, seeking help from teachers is a student's behaviour that has significantly increased in the last decades (Baik et al., 2015). The discrepancy between the results from the AUSSE and the FYES can be explained by differences in the years of administrations of the surveys (2014 versus 2012), the items of evaluation and the population of students evaluated.

Additionally, results from the AUSSE 2012 indicate that first year students reported a lower frequency of academic interactions with teachers than the students in the final years (ACER, 2017b). Also, students enrolled in Australian institutions were less likely to interact with their lecturers and tutors, especially in the first year and perceived less support from their universities in comparison with American students (ACER, 2010).

However, regarding satisfaction with the interactions, students from the USA and Australia have similar perceptions of the interactions with teachers describing them "as good as possible" (ACER, 2010). On the contrary, the results from the SES 2016 (sample size 178,459 students from 95 institutions) that first year students were highly satisfied with the teaching quality (around 83\%) and the support received from academic staff regarding their learning at their universities $\left(75 \%{ }^{2}\right.$ ) (Quality Indicators for Learning and Teaching (QILT), 2017a). Finally, considering the personal dimension of the interactions evaluated by the FYES, $60 \%$ of first year students felt confident that at least one teacher knew their name and this result has remained stable for two decades (Baik et al., 2015).

Even though this body of research offers relevant information for higher education institutions and public policies, it also shows a lack of complexity in the understanding of the interactions that first year students establish with their teachers. The main limitations of these large-scale surveys are that most of these surveys consist of predetermined alternatives and responses, and give no consideration to participants' thoughts and perceptions. Other researchers, including Kuh and $\mathrm{Hu}$ (2001) and Pascarella and Terenzini (1991), have indicated that there is a limited comprehension of the nature of teacher-student interactions because of the extensive use of large-scale surveys. Little is known about the reasons, dynamics, difficulties and advantages experienced by students in the interactions with teachers that are valuable to helping universities to understand this topic. Qualitative studies can address these issues and contribute to the knowledge on teacher-student interactions.

\footnotetext{
${ }^{4}$ These results are based on the percentage of students that agree or disagree with the particular
} affirmation. 


\subsubsection{Qualitative studies on teacher-student interactions.}

A few qualitative studies have explored students' perceptions regarding the nature and quality of interactions with lecturers and teaching assistants in the first year of university. For example, Cotten and Wilson (2006) studied the frequency and quality of teacher-student interactions outside classrooms, their main effects, and determinants regarding students' perceptions. Forty-nine students from a mid-sized public university in the USA participated in nine focus groups. Using purposive sampling, the sample included participants from different year levels, including the first year, and residential and non-residential students.

Similar to the findings of survey-based research examined in the last section, Cotten and Wilson (2006) found that students rarely interacted with their teachers outside classrooms and these interactions had mainly an academic focus. Cotten and Wilson (2006) indicate that students had limited interactions with teachers because students did not perceive the need of seeking teachers outside classrooms. Regarding the effects of the interactions, students reported that interactions with teachers were beneficial to feel comfortable to interact in classrooms and resolve subject-related issues (Cotten \& Wilson, 2006). However, participants also perceived some responsibilities associated with the interactions. Students recognised that when they established interactions with teachers, they felt responsible for performing academically well and made their teachers proud (Cotten \& Wilson, 2006). Finally, participants mentioned factors that facilitated the interactions. Two examples of these factors were students' interest and confidence in their abilities, and teachers' sense of humour (Cotten \& Wilson, 2006). On the other hand, large lectures hindered interactions with teachers, and students considered that teaching assistants were more available to interact (Cotten \& Wilson, 2006).

Grantham, Robinson, and Chapman (2015) conducted a study using an open-ended online survey of two questions asking undergraduate students to nominate exceptional teachers that made a difference in their lives. These questions were part of the "Thank a Teacher" program in a large public American university. Through this research, Grantham et al. (2015) sought the characteristics of meaningful teacher-student interactions among 157 students' responses. The findings suggest that examples of meaningful interactions with teachers were discussions of grades of a particular assessment, academic and professional advice, and caring and respectful treatment in and out of classrooms (Grantham et al., 2015). These results are similar to those presented by Kuh et al. (2010) and Pascarella and Terenzini (1991), some years ago. 
As mentioned in the last section, Hurtado et al. (2011). conducted a mixed method study In the qualitative section, Hurtado et al. (2011) studied the first year experience of 71 Science students from five campuses of American tertiary institutions. Third year students, $60 \%$ women, participated in semi-structured focus groups sharing their first year experiences of the interactions with Science faculty teachers. The findings show that students felt confident to interact with teachers when they showed their availability and willingness to interact during classes through attitudes such as promoting students' participation (Hurtado et al., 2011). Regarding the quality of the interactions, participants perceived that interactions with teachers in large classes were more impersonal than in tutorials where the size of classrooms was smaller (Hurtado et al., 2011).

Finally, two recent qualitative studies that have studied the experience of first year students were conducted in China. Zhang, Hu, and McNamara (2015) analised student' engagement conducting eight semi-structured interviews and four focus groups with 30 undergraduate students from different year levels. Among the participants, there were nine first year students. Coinciding with the study of Cotten and Wilson (2006) that was conducted almost ten years ago, Zhang et al. (2015) found that students reported a low frequency of interactions with their teachers outside classrooms and only a few interactions occurred during or immediately after lectures. Most of the participants mentioned that large classes were a barrier for establishing one on one interactions with teachers (Zhang et al., 2015).

The second study is from Chan, Tong and Henderson (2017) who studied the experiences of 56 first and final year nursing students. In focus groups, students described their perceptions of teacher-student relationships and power dynamics in the university. Chan et al. (2017) reported that students had limited interactions with their lectures, even in classrooms, and students interacted more frequently with their tutors. Regarding the benefits of these interactions, participants considered that interactions with teachers played a vital role in their learning, especially in the improvement of motivation and engagement with a particular subject (Chan et al., 2017). Also, participants reported that prior negative experiences with staff and large classes hindered the interactions with teachers (Chan et al., 2017).

Additionally, there are a few examples of qualitative studies in Australia that have investigated teacher and student interactions indirectly. Larkin, Rowan, Garrick, and Beavis (2016), for instance, studied first year students' perceptions of first year initiatives for engagement developed in a particular Australian university. Larkin et al. (2016) conclude that 
students who positively evaluated the activities were those who received support from academic staff and who interacted with teachers in these activities. Another example is Good, Colthorpe, Zimbardi, and Kafer (2015) who examined the views of first year students regarding the teaching styles of tutors and how these styles promoted positive interactions in classrooms in a particular subject. Good et al. (2015) conclude that a personalised teaching style in which teachers focused on students' needs facilitated interactions with students and improved their academic performance in the subject.

In conclusion, this body of research on teacher-student interactions in higher education suggests that there is a low frequency of interactions in and outside classrooms. The majority of interactions that students had with teachers are related to academic purpose. Besides, it seems that tutors have a vital role in promoting interactions with students because tutorials usually have smaller groups in comparison to lectures. Findings of the qualitative studies reviewed suggest that particular students' and teachers' characteristics play a role in the interactions. For instance, students' interest and motivation to actively seek help and teachers' disposition to interact in and outside classes.

\subsection{Final Comments}

Some aspects of the research on teacher and student interactions in higher education require some analysis. For example, the different settings where studies have taken place is an important factor to consider. A main body of research has studied first year students in residential colleges where the majority of students live on campus and interact with the academic staff in different ways than commuter students, or those who do not live at the university. The evidence in this area has focused predominantly on the interactions outside classrooms and their benefits for students' educational experience (Cox, 2011; Cox \& Orehovec, 2007; Komarraju et al., 2010). Additionally, other studies reviewed before have examined students' perceptions of interactions with staff in community colleges that often have two-year courses and prepare students from different backgrounds to start a degree in the university (Lundberg, 2014; Wirt \& Jaeger, 2014). Students who are part of community college often left their previous secondary or tertiary studies, and some researchers consider that this population could be vulnerable in economic, social and cultural terms (Lundberg, 2014; Wirt \& Jaeger, 2014). 
Considering the relevance of the context for qualitative studies, research with residential students and community colleges presents a specific setting to understand teacher and student interactions that vary from the Australian reality. In the Australian higher education context, the majority of students commute to the institutions taking courses of three to four-year average (Australian Qualifications Framework Council, 2013). The difference between institutional settings suggests the need to understand students' experiences at Australian universities that can vary from those students in residential and community colleges, particularly in the first year. This study contributes to filling the gap of knowledge of students' experiences about interactions with their teachers in the first year evaluating the context of one large public Australian university.

The qualitative studies reviewed in the last section have examined students' perceptions of teacher-student interactions. These studies have contributed to the knowledge, specifically of the frequency of interactions and factors that facilitate and hinder the interactions in higher education (Chan et al., 2017; Cotten \& Wilson, 2006; Hurtado et al., 2011; Zhang et al., 2015). However, little is known about the quality of teacher and student interactions and their influences on a broad range of academic factors, including motivation, engagement and learning. Although some qualitative studies have suggested the benefits of teacher and student interactions on learning and motivation, for example, Zhang et al. (2015), there is a lack of evidence about the effects of the interactions on students' sense of belonging to institutions.

One of the reasons for this lack of focus on students' sense of belonging may be that some studies have included participants from the first to the fourth year and others only final year students (Cotten \& Wilson, 2006; Hurtado et al., 2011). Evaluating only the experiences of final year students can be considered as a limitation to understand the relevance of teacherstudent interactions. It is known from the survey-based evidence that final year students interact more regularly with academic staff establishing personal types of relationships with them, for example, mentoring and research assistance (Kuh et al., 2010; Pascarella \& Terenzini, 1991). In this context, when research includes older students, it misses the opportunity of knowing the students' experience of the first year, which is considered one of the most difficult and challenging years in the university (Christie et al., 2016; Gibney et al., 2011). The first year is when interactions with staff can make a real difference in the learning experience of students. Therefore, understanding the influences of teacher and student interactions could support specific interventions in and out classrooms to encourage positive interactions between teachers and students in the first year. 
Finally, survey-based research and qualitative studies report significant evidence about the interactions between teachers and students outside classrooms, especially in residential contexts, and their influences on motivation and learning (Pascarella \& Terenzini, 1991). However, there is insufficient evidence about the interactions inside classrooms and their links, if any, with interactions outside. Knowing this aspect is relevant in the Australian context where students spend most of the time with their teachers in classes and the interactions that may be established in those settings can be fundamental for academic and social outcomes.

Considering the research on teacher and students interactions reviewed, this study examines teacher and student interactions in the first year from students' perspective in a large public Australian university. This research contributes to the comprehension of the frequency, quality and effects of the interactions that students establish with lecturers and tutors in the first year of university. 


\section{Chapter 3 Methodology}

Large-scale education research on teacher and student interactions has suggested that frequent and high-quality interactions between academic staff and students encourage motivation, engagement, learning and sense of belonging to institutions (Astin, 1999; Pascarella \& Terenzini, 1991; Ryan \& Deci, 2000; Tinto, 1993). Although many studies have indicated the benefits of teacher-student interactions, little is known about the nature and effects of the interactions from students' experiences and perceptions, especially in the first year.

This study aims to examine teacher and student interactions in the first year of university in one large public Australian university guided by two research questions:

a) What are the expectations and experiences of undergraduate students regarding the interactions with their tutors and lecturers in the first year of university?

b) How have these interactions influenced their motivation, engagement, learning, and sense of belonging to their university?

This chapter outlines the methodology of this study showing the strengths of qualitative methodology to answer the research questions. This chapter consists of two sections. First, there is a review of the research design of the study including the use of semistructured interviews in the data collection process and thematic analysis for the data analysis. The second section discusses the strategies taken to assure rigour and trustworthiness of this study including ethical aspects.

\subsection{Research Design}

\subsubsection{Methodological framework and worldview.}

This project is a small-scale study of one year from July 2016 to July 2017. It employed a qualitative methodology that enabled a profound understanding of subjective students' experiences of their interactions with academic staff in the first year. This research was developed within the social constructivist worldview considering that students build their subjective expectations and experiences in the interactions with others. Constructivism is one of the main worldviews to understand reality and postulates that individuals develop personal, diverse and complex meanings of their experiences within a particular context (Creswell, 2014). This research assumes that students interpret and give meaning to their 
experiences of interactions with their teachers and that these experiences are varied and complex, especially considering the different academic contexts, personal characteristics and backgrounds.

\subsubsection{Recruitment procedures.}

The recruitment of participants was a challenging process implemented for seven months. The first goal was to recruit 60 participants but the timing of the semester made difficult the process. In the end, 21 students joined the research. All participants met the following inclusion criteria: being 18 years old or more, studying a Bachelor degree in the university and being enrolled in the first or second year of their degrees.

The process of recruitment consisted of three steps: contacting key stakeholders, posting announcements, and snowballing. First, the researcher contacted first year coordinators and lecturers of main faculties including Arts, Science, and Business, and students' representatives for assistance in publishing an announcement in the student portal and social media. Second, posters with the invitation to the study were displayed in every building of the university in places visible to students. Finally, the researcher asked participants to invite other students to join the research through snowballing that occurred on three occasions.

\subsubsection{Participants.}

The context of the participants was a large public Australian research university with around 45,000 students, 6,500 staff and nine undergraduate degrees. This institution is located in one of the main cities of Australia and is part of the group eight of leading Australian universities. This urban university has a strong focus on research, learning and teaching, and engagement programs. In terms of classroom sizes, the number of students per lecture can range from 60 to 500 people and tutorials often consist of 10 to 30 people. The majority of first year students who enrol in this institution come directly from high school. In 2014, this university achieved high rates of retention (over 92\%) and completion of students (over 90\%) (Australian Government Department of Education and Training, 2014). In comparison with other Australian higher education institutions, recently undergraduate students evaluated this university with high scores on key aspects of the educational experience gauged in the Student Engagement Survey (SES) (Quality Indicators for Learning 
and Teaching (QILT), 2017b). Four dimensions were evaluated with scores (percentage of agreement) around $80 \%$, quality of educational experience $\left(79.7^{*} / 79.9^{+}\right)$, teaching quality $\left(83.2^{*} / 81.5^{+}\right)$learning resources $\left(86.31^{*} / 85.2^{+}\right)$and students' skills development through their studies $\left(79.2^{*} / 81.2^{+}\right)($QILT, 2017b). On the other hand, students evaluated relatively with lower scores dimensions about students' sense of belonging to the institution $\left(62^{*} / 64.2^{+}\right)$, and institutional support for administrative and teaching activities $\left(63.5^{*} / 72^{+}\right)$(QILT, 2017b).

After the recruitment process, the sample consisted of 21 undergraduate students between 18 and 24 years old and the average age was 20.1 ( $\mathrm{SD}=1.75)$. All participants were enrolled in their first or second year of university ${ }^{5}$ and had at least one semester of experience in their degrees. Table 3.1 shows the participants' sociodemographic and educational characteristics.

Table 3.1 Participants' socio-demographic and educational characteristics

\begin{tabular}{|c|c|c|}
\hline \multicolumn{2}{|c|}{ Characteristics } & \multirow{2}{*}{$\frac{\text { Number of students }}{17}$} \\
\hline & Women & \\
\hline Sex & Men & 4 \\
\hline \multirow{2}{*}{ Type of student } & Domestic & 11 \\
\hline & International & 10 \\
\hline \multirow{2}{*}{$\begin{array}{l}\text { First in family } \\
\text { to enrol in a } \mathrm{HEI}^{6}\end{array}$} & Yes & 6 \\
\hline & No & 15 \\
\hline \multirow{2}{*}{ First tertiary degree } & Yes & 17 \\
\hline & No & 4 \\
\hline \multirow{6}{*}{ Bachelor } & Arts & 7 \\
\hline & Science & 9 \\
\hline & Biomedicine & 2 \\
\hline & Commerce & 1 \\
\hline & Environment & 1 \\
\hline & Music & 1 \\
\hline
\end{tabular}

\footnotetext{
* Average percentage of the university participating in this study.

${ }^{+}$Average percentage of all Australian higher education institutions.

${ }^{5}$ The recruitment process considered two academic semesters. Semester 22016 and Semester 12017.

${ }^{6}$ Higher Education Institution.
} 


\subsection{Data Collection Methods}

In this research, the participants were asked to take part of one semi-structured interview where they reflected retrospectively about their expectations and experiences with lecturers $^{7}$ and tutors ${ }^{8}$. The interviews were guided by a protocol of questions (See Appendix 1). The clarity and relevance of the questions were evaluated in a pilot focus group conducted with graduate education students. The final version of the protocol presented in Appendix 1 incorporated all feedback and suggestions from the pilot focus group.

Seventeen semi-structured interviews were conducted face to face by the researcher at the university at times that suited students. Due to the availability of students, four interviews were implemented in pairs in which each participant had equal time to answer the questions. All interviews were audio-recorded taking an average of 42 minutes. The data collection process was conducted between November 2016 and May 2017.

On the one hand, semi-structured interviews as qualitative data collection methods have four main advantages for this study. First, semi-structured interviews can be conducted with clear key research topics and questions that facilitate to obtain the information sought by the researcher in a short period (Minichiello, Aroni, \& Hays, 2008; Patton, 2002). Achieving rich data in a short time frame was fundamental for this research as it was a one-year study. Additionally, having a protocol with questions enables the comprehension of the data making the process of data collection more systematic and rigorous (Patton, 2002). Third, in semistructured interviews, participants are more likely to feel comfortable to talk about diverse topics using their own words to answer open-ended questions facilitating a broad understanding of their experiences (Minichiello et al., 2008; Patton, 2002). Finally, semistructured interviews give focus to the researcher but also flexibility in posing follow-up questions that enable an in-depth comprehension of the participants' experiences (Minichiello et al., 2008; Patton, 2002).

On the other hand, semi-structured interviews have two main challenges. Because a protocol of questions guided the interviews, it may be possible that the researcher could omit some relevant and salient topics jeopardising the understanding of participants' experiences

\footnotetext{
${ }^{7}$ Participants were part of large cohorts of Bachelor degrees. When they describe lectures, they consider large classrooms size (100-200 students) and tutorials are smaller (average 20 students). For the majority of students, lecturers teach lectures and tutors teach tutorials.

${ }^{8}$ In the university studied, the majority of tutors in large cohort Bachelor degrees are graduate research students.
} 
(Patton, 2002). To face this challenge in the present study, all interviews were audio-recorded and transcribed to ensure all participants' answers were considered in the data analysis. A second limitation of semi-structured interviews is that researcher's presence might bias participants' responses (Creswell, 2014). To address this issue, the researcher carefully reviewed the three first interviews (recordings and researcher notes) to evaluate her performance as interviewer identifying any verbal and nonverbal sign that could influence participants' answers. After this analysis, some key questions were formally included in the final version and the interviewer elaborated a more effective time organisation to prioritise central questions. This preliminary analysis of the interviewer's performance helped the development of the following interviews. Finally, the researcher was independent and had no power based on relationships with the participants.

\subsubsection{Procedure.}

Once students had received information about the study, they emailed the researcher if they wanted to participate with times and dates of availability for interviews. After an appointment had been made, the participants met with the researcher face to face in a private room in a faculty of the university. At the beginning of the interviews, all participants were asked to read the plain language statement (Appendix 2) and sign the informed consent (Appendix 3), both with a detailed explanation of the research's aim and students' role in the study. Once participants signed the informed consent, they filled a brief socio-demographic questionnaire (Appendix 4). At the end of the interviews, students received three coffee vouchers as a reimbursement for the time spent in the study.

\subsection{Data Analysis}

The data from the interviews was analysed using thematic analysis that consists of systematically reducing the data describing meanings through the identification of patterns and codes (Boyatzis, 1998; Braun \& Clarke, 2006; Patton, 2002; Schreier, 2013). This type of analyses facilitated to find common and relevant topics in the data to answer the study research questions. Figure 3.1 shows the stages of the data analysis of this study. 
Figure 3.1 Stages of the data analysis of this study

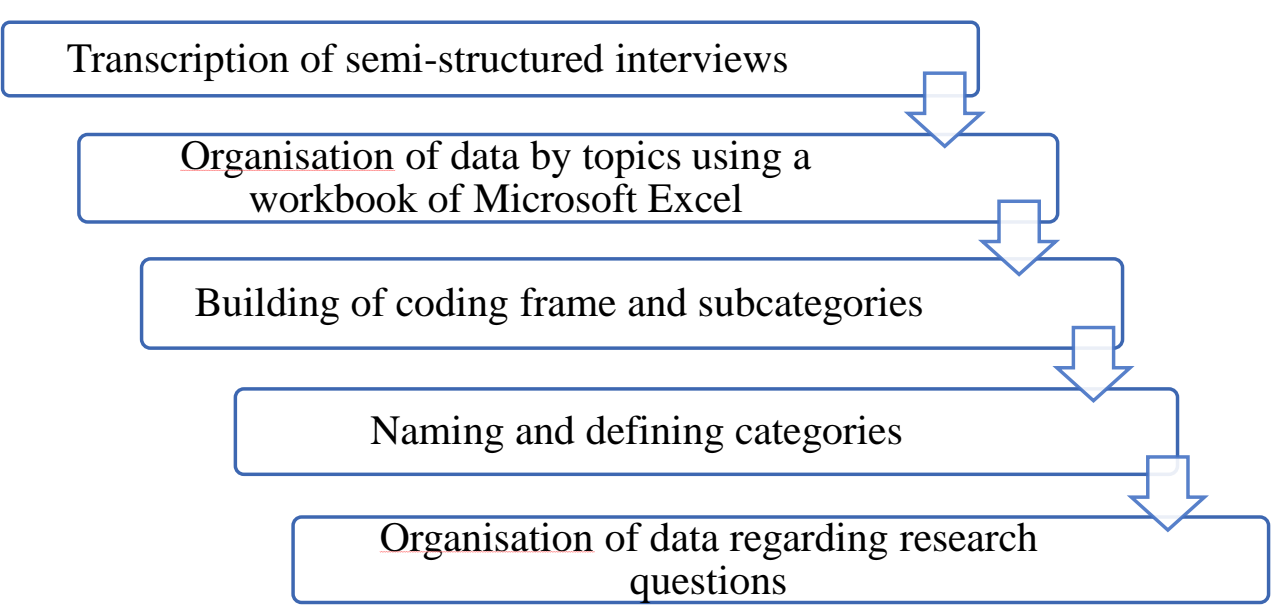

First, the researcher transcribed the 17 interviews using Microsoft Word 2016, including the interviewer interventions to ensure all information provided by the participants was reflected in the transcriptions (Braun \& Clarke, 2013). All participants' names were replaced by pseudonyms and codes to guarantee their anonymity. The coding convention consisted of identifying each participant with the initials of their bachelor degrees and a unique number by bachelor degree. For example, BA_2 refers to the second participant of Bachelor of Arts, and BS_4 corresponds to the fourth participant of Bachelor of Science. The interviews were identified with the initial such as I (interview) and with a unique number. For instance, I15 corresponds to the interview number 15. Table 3.2 presents the coding convention of participants used in this research.

Table 3.2 Coding convention of participants in this research

\begin{tabular}{ll}
\hline \multicolumn{1}{c}{ Code } & \multicolumn{1}{c}{ Meaning } \\
\hline BA & Bachelor of Arts \\
BS & Bachelor of Science \\
BB & Bachelor of Biomedicine \\
BE & Bachelor of Environment \\
BM & Bachelor of Music \\
BC & Bachelor of Commerce \\
I & Interview \\
\hline
\end{tabular}

After reading the transcriptions, the data was organised by topics such as expectations, experiences, the rating of experiences, influences of interactions, suggestions and other themes in a workbook of Microsoft Excel 2016. Each sheet of the workbook contained data 
from the transcriptions for each topic organised in the following columns: interviews, participants (code), answer, code, topic and subtopic.

The third step involved coding the data and then building a coding frame of main categories and subcategories, including names and definitions (Boyatzis, 1998; Schreier, 2013). Schreier (2013) states that coding frames should accomplish certain requirements such as unidimensionality that means main categories should cover only one aspect of the material. For example, in this research, two different categories were expectations and experiences. Also, mutual exclusiveness indicates that categories should not have same codes. For instance, the present research used different codes for frequency and quality of the interactions. The last requirement is exhaustiveness; each category should have all relevant data related to it (Schreier, 2013). The researcher assigned codes to the data and then organised them in subtopics and topics considering the Schreier's requirements. The codes used were develop based on emergent data from participants, for example, the code "feeling close to tutors", and predetermined codes appropriate for the data, for instance, "teachers' understanding of students' needs". Appendix 5 shows one example of coding, subtopics and topics related to the negative characteristics of the quality of interactions reported by one participant. Figure 3.2 illustrates an example of the organisation of codes, subtopics and topics. In this example, the codes were grouped by two positive characteristics of the quality of the interactions. 
Figure 3.2 Coding frame of two positive characteristics of the quality of interactions

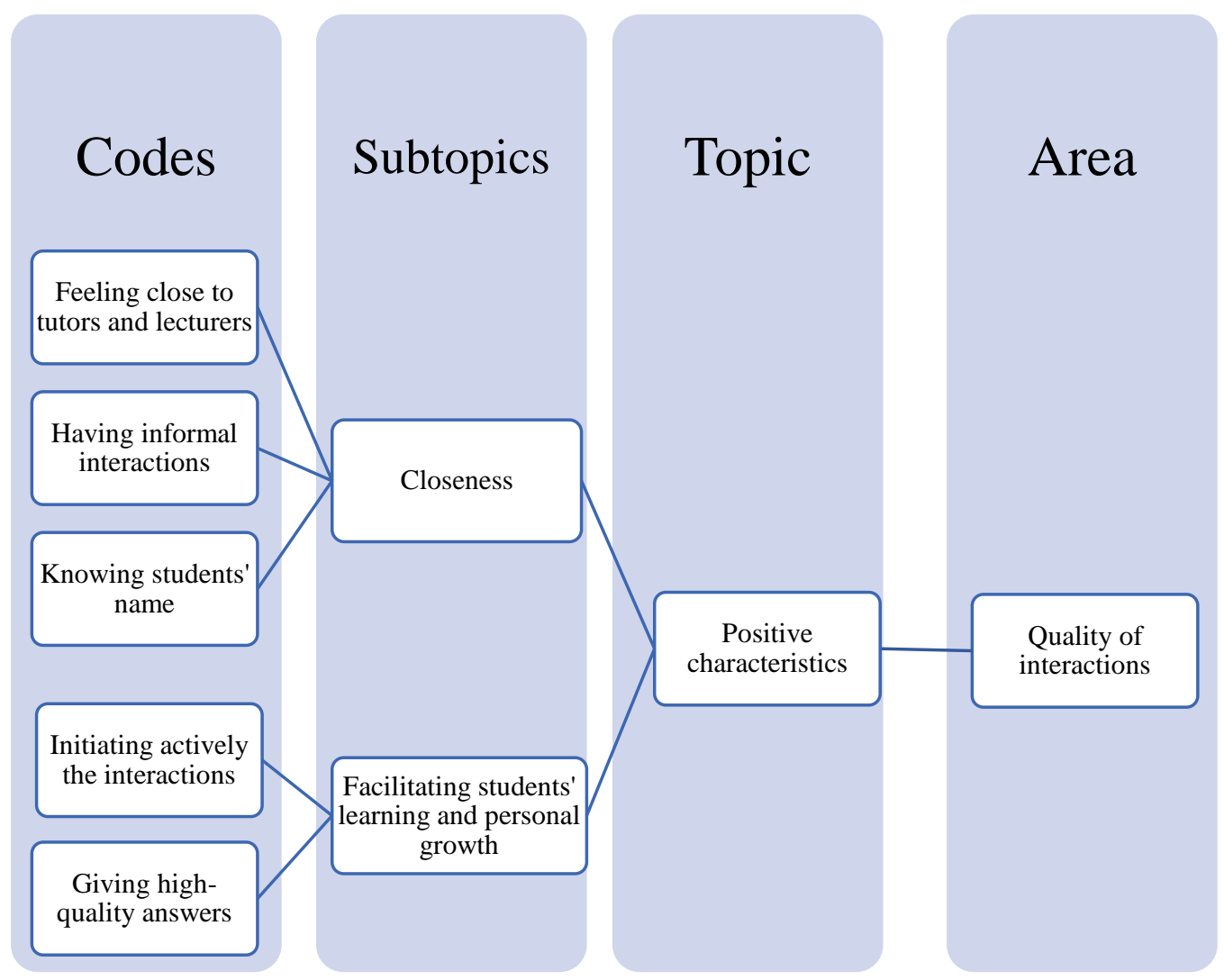

Once the data was coded, the researcher and co-researchers (thesis' supervisors) reviewed the coding and made suggestions to expand when it was necessary regarding the data. Then, to evaluate the coding consistency, Schreier (2013) suggests dividing the material into topics organising each unit into exactly the categories or subcategories. This research followed this strategy, and finally, the researcher arranged and interpreted the data regarding the research questions of the study: participants' expectations and experiences of teacherstudent interactions and perceived benefits. From this analysis, common themes of expectations and experiences began to appear in the data that may suggest an approaching to the data saturation in this particular sample.

Boyatzis (1998) and Braun and Clarke (2013) have identified some weaknesses in the thematic analysis. One of them is the difficulty in determining the voices of the participants because the focus is searching general patterns rather than specific experiences. Therefore, researchers may not undertake analysis and claims about the language of participants. This research did not seek an examination of the language of participants instead it aimed to find commonalities and differences in the students' experiences regarding the interactions 
between teachers and students. However, once the researcher identified major themes, she selected representative students' quotes to illustrate each topic.

\subsection{Quality of the Study: Rigour and Trustworthiness}

According to Yin (2010), three factors make a qualitative study trustworthy and credible: transparency, methodic-ness and adherence to evidence. Yin (2010) states that qualitative procedures, assumptions and decisions of a study should be described and documented. In that way, the information is transparent and available for reviewing and understanding. In this study, researchers' notes of interviews and decisions during the process are clearly documented in notebooks, as well as in the transcriptions.

The second aspect is methodic-ness and is related to transparency. Yin (2010) claims that a qualitative research should be conducted methodically "means following some orderly set of research procedures and minimizing whimsical or careless work" (p.20). Through this way, researchers would avoid bias and unintentional alterations of the process. The present study followed a protocol for the data collection methods, recruitment of participants and data analysis as described before. Also, the researcher registered all steps and decisions taken in a notebook throughout the study.

The last element refers to adherence to evidence. Yin (2010) states that "qualitative research should be based on an explicit set of evidence" (p.20) that means employing participants' expressions and experiences as they described them. To address this aspect, the researcher elaborated the transcriptions of the interviews to use original quotes of participants in the data analysis and presentations of findings.

Creswell (2014) indicates that qualitative studies show strength when the results are valid and accurate from the perspectives of participants and researcher. Creswell (2014) describes some strategies to encourage validity in studies. This current study addressed three strategies: researcher triangulation, member checking and peer debriefing (Creswell, 2014). To ensure triangulation of the data, the researcher asked two co-researchers (thesis' supervisors) to evaluate appropriateness, consistency and accuracy of the data analysis and the interpretation of findings. Member checking was the second strategy adopted by the study and consisted of asking participants to review the consistency and accuracy of some topics generated by the data. Three participants were contacted by email and asked about the consistency of three main topics, subtopics and codes generated by their interviews. Participants' feedback and suggestions were accounted in the final interpretation of the data. 
Finally, this study also considered peer debriefing. The researcher presented an overview of the study (aims, questions, problem, and methodology) and main findings to an audience of experts in higher education who gave feedback and recommendations regarding the methodology and interpretation of the results. This final presentation of the research included the experts' comments.

\subsection{Ethical Considerations}

This study was considered to have minimal risks for the participants. The Human Ethics Advisory Group (HEAG) of the Melbourne Graduate School of Education approved the development of the study (Ethics Id. No.: 1647683) in October 2016. Appendix 6 shows the letter of approval. 


\section{Chapter 4 Findings}

This chapter presents the analysis of the findings from 17 semi-structured interviews with 21 undergraduate students. Participants were asked about their expectations and experiences of the interactions with tutors and lecturers in the first year and the influences of these interactions on motivation, engagement, learning, and sense of belonging to the university. This chapter consists of three sections. The first section analyses the findings regarding students' expectations and experiences of the interactions, and purposes of the interactions. Also, the first section examines participants' perceptions of the factors that facilitated and impeded teacher and student interactions and the characteristics of positive and negative interactions. The second section analyses students' views about the benefits of teacher and student interactions. Finally, the third section highlights the main findings leading to a discussion of their implications in the next chapter.

\subsection{Teacher-Student Interactions: Expectations and Experiences}

Students reported different expectations of the interactions with lecturers and tutors that were related to the classrooms settings of lectures and tutorials. In the case of lecturers, the recurrent topic was having low expectations about the frequency and quality of the interactions. Three quarters of participants expected to have limited, or no interaction with lecturers in classrooms and those few interactions would be formal and distant. Most of participants thought that large numbers of students per class would be a barrier to establishing close interactions with academic staff. On the other hand, half of students had high expectations about the interactions with tutors regarding frequency and quality. Students thought the interactions would be frequent developing a close connection with tutors, especially because the classes would be smaller than lectures and similar to high school classrooms.

A recurrent topic among the interviews was the comparison between teacher-student interactions in secondary schools and universities. This topic can be associated with how recent high school experiences were for participants. Some students shared the expectation that interactions with tutors would have some similarities and differences to those frequent and intimate interactions that they had with high school teachers. It can be particularly relevant because most of the students in this study (17/4) were transitioning from high school 
and adjusting to a new university context. As Pascarella and Terenzini (1991), and Tinto (1993) have indicated, teacher-student interactions are key to encourage the adjustment of students in the first year of university. Table 4.1 shows students' expectations regarding the interactions with teachers and their relevance in the first year.

Table 4.1 Examples of students' expectations

\begin{tabular}{ll}
\hline \multicolumn{1}{c}{ Topic } & \multicolumn{1}{c}{ Students' quotes } \\
\hline $\begin{array}{l}\text { Interactions with } \\
\text { lecturers }\end{array}$ & "I feel like lectures you go and listen to what they say" (I16, BB_2). \\
$\begin{array}{l}\text { Interactions with } \\
\text { tutors }\end{array}$ & $\begin{array}{l}\text { I heard that [tutorial] was more like classrooms, so I thought it will be like } \\
\text { individual kind of help like they prompt a question, anyone gets hand on the } \\
\text { question, and they come and probably be like go around and see that everyone is } \\
\text { doing the questions and if anyone has any problem (I10, BS_4). }\end{array}$ \\
$\begin{array}{l}\text { Interactions with } \\
\text { high school } \\
\text { teachers }\end{array}$ & $\begin{array}{l}\text { I knew that it wasn't like high school 'cause you get a lot of support [...] in high } \\
\text { school, there are 20 students in a class, so the teacher can just come around to } \\
\text { you, you can see them at lunch time. They're always there, and they want you to } \\
\text { pass (I13, BS_8). }\end{array}$ \\
\hline
\end{tabular}

Regarding the actual experiences of students, there were similarities and differences between students' expectations and the interactions that they had with teachers in the first year. Table 4.2 illustrates the most representative experiences that students had with lecturers and tutors.

Table 4.2 Examples of students' experiences

\begin{tabular}{ll}
\hline \multicolumn{1}{c}{ Topic } & \multicolumn{1}{c}{ Students' quotes } \\
\hline $\begin{array}{l}\text { Interactions } \\
\text { with lecturers }\end{array}$ & $\begin{array}{l}\text { "I don't think there's many interactions, sometimes the lecturer asks a question, but } \\
\text { then, if there's a smaller lecture, people would answer, but if it's a big lecture hall, } \\
\text { of } 300 \text { people, then no one would want to answer" (I12, BS_7). }\end{array}$ \\
$\begin{array}{l}\text { Interactions } \\
\text { with tutors }\end{array}$ & $\begin{array}{l}\text { "There's more frequency [in tutorials], we can ask questions, and they [tutors] } \\
\text { would explain what we don't understand" (I17, BS_6). }\end{array}$ \\
& $\begin{array}{l}\text { There is a lack of interaction like tutors just talk us on the tutorial but not so close } \\
\text { with our own assignment [...] in China they might ask frequently the students } \\
\text { assignments, they track the project of the student, it's a more a personal tutorial but } \\
\text { here is like one tutor with many students like a teacher not a tutor (I5, BE_1). }\end{array}$
\end{tabular}

In the case of the interactions with lecturers, there was a match between what students expected of the interactions and their actual experiences, particularly, in terms of frequency 
and quality of interactions in classrooms as seen in the students' views in Table 4.2. More than half of students found that in classes, there were few, if any, interactions with lecturers. Although students experienced limited interactions with lecturers in classrooms, many of them were satisfied with this frequency arguing that the role of lecturers was to deliver the content during classes. Therefore, any attempt by students or professors to interact was perceived by some as disruptive to the flow of the class. This finding can show the relevance of students' preconceptions of teaching strategies in particular classes that could influence their disposition to interact with teachers in classrooms, especially in the first year. In fact, Pascarella (1980) and Tinto (1993) have indicated that students' beliefs, preconceptions and backgrounds influence teacher-student interactions.

Additionally, almost all participants reported having more interactions with tutors than lecturers, probably because they saw their tutors more times per week (two or three times) than lecturers. However, their expectations of closeness and frequency were often not met, particularly for those students that expected to interact with tutors in similar ways as interacting with high school teachers. There was a mismatch between participants' expectations and their actual experiences of interactions with tutors. It could be a result of a discrepancy between students' preconceptions of tutors' role and their experiences in the first year. This discrepancy may influence the levels of satisfaction of students with their academic experience and how they cope with their transition, as other researchers suggested (Brinkworth, McCann, Matthews, \& Nordstrom, 2009).

Based on the expectations and experiences with lecturers and tutors, three quarters of participants offered suggestions to improve the frequency and quality of interactions in the first year of university. Table 4.3 shows two representative students' recommendations.

Table 4.3 Examples of students' suggestions

\begin{tabular}{ll}
\hline \multicolumn{1}{c}{ Topic } & \multicolumn{1}{c}{ Students' quotes } \\
\hline $\begin{array}{l}\text { Interactions } \\
\text { with lecturers }\end{array}$ & $\begin{array}{l}\text { I guess what would be really reassurance for students like particularly in the first } \\
\text { year it's to let them know they're there to help you and feel free to ask any questions } \\
\text { or "come to see me after the lecture if you're not sure about anything" or tell them } \\
\text { to like slow down or repeat something they're not sure (I3, BS_1). }\end{array}$ \\
$\begin{array}{l}\text { Interactions } \\
\text { with tutors }\end{array}$ & $\begin{array}{l}\text { Tutors should be reminded that these are first year students, they don't as confident } \\
\text { as second and third year students, they should be reminded they need to help the } \\
\text { students, they need to interact with the student rather than letting students interact } \\
\text { with them (I6, BS_2). }\end{array}$
\end{tabular}


As seen in Table 4.3, when some participants reflected about the match and mismatch between their expectations and experiences, they suggested that academic staff should take an active role in encouraging students to seek academic help, for example, informing them about the options and places to do that. More than half of participants shared the perception that teachers should promote participation in classes through asking questions and stimulating discussion. For example, the following student's quote:

I think lecturers should do more instead of just reading they should fine a new ways of interacting with the cohort like asking questions and getting the whole audience to answer that question (I16, BB_2).

Also, teachers should explain the relevance of teacher-student interactions for learning to first year students. Teachers' active role in promoting interactions was considered critical for the first year of university when students are adjusting to the educational process transitioning from high school and often are not confident to seek help or ask questions. Through these suggestions, participants showed a need for guidance in their transition emphasising the teachers' vital role in this process as indicated by higher education transition models (Pascarella, 1980; Pascarella \& Terenzini, 1991; Tinto, 1993).

\subsubsection{Typology of teacher-student interactions.}

All participants reported different types of teacher-student interactions in the first year that were grouped into three broad categories: academic, social and nonverbal. Table 4.4 shows the categories and types of the interactions organised by frequency. A student's example explains each type of interaction. As seen in Table 4.4, most of the interactions reported had an academic purpose that could reflect the educational relevance of the interactions in the first year of university. 
Table 4.4 Categories and types of teacher-student interactions

\begin{tabular}{|c|c|c|}
\hline Category & $\begin{array}{l}\text { Types of } \\
\text { interaction }\end{array}$ & Students' quote \\
\hline \multirow[t]{2}{*}{ Academic } & Clarifying content & $\begin{array}{l}\text { "They [questions] are about the subject, the knowledge we are } \\
\text { learning during the last week or the learning materials that we } \\
\text { are doing in the tutorials" (I9_BS_3). }\end{array}$ \\
\hline & Discussing ideas & $\begin{array}{l}\text { With tutors, I usually like to talk in class, so I will usually } \\
\text { bring my own statements about what we're talking about, and } \\
\text { then we would be able to have a little bit of discussion about } \\
\text { it, so one on one interaction (I7, BA_4). }\end{array}$ \\
\hline \multirow[t]{3}{*}{ Academic } & $\begin{array}{l}\text { Clarifying criteria } \\
\text { and aims of } \\
\text { assessments }\end{array}$ & $\begin{array}{l}\text { I sometimes didn't understand what I need it to do for an } \\
\text { assignment or what I need it to improve if I had previous } \\
\text { assignments, so speaking to them help me to understand what } \\
\text { the lecturer or the subject was looking for (I8, BA_5). }\end{array}$ \\
\hline & $\begin{array}{l}\text { Seeking career } \\
\text { advice and field } \\
\text { related information }\end{array}$ & $\begin{array}{l}\text { "Sometimes I asked about their degree because I wanna do } \\
\text { engineering and most of my subjects are engineering subjects } \\
\text { and all the tutors are master of engineering students, so I } \\
\text { wanted to ask them if it has been rewarding" (I12, BS_7). }\end{array}$ \\
\hline & $\begin{array}{l}\text { Helping to } \\
\text { understand the } \\
\text { content }\end{array}$ & $\begin{array}{l}\text { "When they answer my questions, they provide advice and } \\
\text { how to understand or what I can do to understand like 'here's } \\
\text { a link you can read more information in that link' or in that } \\
\text { book" (I9, BS_3). }\end{array}$ \\
\hline Social & Casual talk & $\begin{array}{l}\text { "[Lecturers usually make] jokes about the weekend, cricket or } \\
\text { current affairs, like what is happening in the world or like any } \\
\text { way to kind of interact with people younger" (I4, BA_3). }\end{array}$ \\
\hline $\begin{array}{l}\text { Nonverbal } \\
\text { interactions }\end{array}$ & Eye contact & $\begin{array}{l}\text { "If you sit in the front row, maybe you can have eye contact } \\
{[\ldots] \text {, but if you sit in the back, there's no eye contact at all" }} \\
\text { (I9, BS_3). }\end{array}$ \\
\hline
\end{tabular}

As examined in the literature review, the typology of Cox and Orehovec (2007) describe five types of interactions from disengagement or no interaction to mentoring, in which teachers and students interact for academic and personal purposes. Also, Cox and Orehovec (2007) describe incidental contact as interactions that occur unintentionally because faculty and students are in the same place. Then, functional interactions have an academic purpose, and personal interactions have a personal aim of any of both parts (teachers or students). As seen in Table 4.4, the most frequent type of interactions in and outside classrooms between students and academic staff was academic related, especially interactions related to content, feedback and discussion of ideas. These kinds of academically 
related interactions correspond to the functional type of the study of Cox and Orehovec (2007) that was the second most frequently found in their study.

Some participants reported limited social and nonverbal interactions including casual talk and eye contact. It can be argued that these two types of interactions had an indirect academic purpose, for example, connecting with students in classes and encouraging their engagement which are not considered in the typology of Cox and Orehovec (2007) that focuses on interactions outside classrooms. In the current study, participants did not report interactions with personal purposes and mentoring as in Cox and Orehovec's (2007) typology. It is probable that because interviewees were enrolled in the first and second years, they did not experience these types of interactions. Cox and Orehovec (2007) included students from different year levels, particularly final year students, who are more likely to establish close and personal interactions with their teachers (Kuh et al., 2010).

Students mentioned that the majority of the interactions with tutors and lecturers occurred inside classrooms, but also, they interacted out of classrooms through consultation hours and emails. Both types of interactions facilitated students to ask individual and specific questions in a one on one interaction with teachers, face to face in consultation hours and online by emails. Three quarters of participants interacted in consultation hours with lecturers and used emails to interact with tutors. However, it seems that these kinds of interactions, especially, consultation hours were rarely used for the general cohort of first year students at the university. Some participants emphasised that only a few students used consultation hours, as the following student points out:

I get the impression that not many people do [use of consultation hours] until later in the term when they don't know what to do for the assignment or something but they don't go and see them in the first couples of weeks to know what's going on in the lecturers (I11, BB_1).

Reflecting on the reasons for the limited used of consultation hours, some participants perceived that there was a lack of available information about this type of interaction in their subjects, as the following student describes:

Like office hours of one of my subjects, no one really knows about it. There was no announcement, so if you want to know you should really 
search it up, and so a lot of people don't really bother, lots of students don't even know about it in the first place (I12, BS_7).

Students suggested that teachers should actively promote these interactions, especially for first year students. It highlights the active and crucial role that academic staff plays in the first year transition that was mentioned by participants in the present study and has been indicated in the literature (Tinto, 1993).

\subsubsection{Determinants of teacher-student interactions.}

The interviews revealed certain factors that were perceived to facilitate and hinder teacher and student interactions in the university. Participants mentioned factors related to four categories: student, institution, peers and teacher. Table 4.5 presents an overview of the main perceived factors and indicates in bold the most frequent determinants, teachers' disposition to interact and classrooms size, especially large class size. On the other hand, the least common factors were related to the categories of student and peers. Each factor will be analysed later in this section giving particular participants' examples.

Table 4.5 Determinants of teacher-student interactions

\begin{tabular}{lll}
\hline Category & \multicolumn{1}{c}{ Facilitators } & \multicolumn{1}{c}{ Barriers } \\
\hline Student & $\begin{array}{l}\text { High levels of preparedness and } \\
\text { confidence }\end{array}$ & Low levels of preparedness and confidence \\
\hline Institution & Small classroom size & Large classroom size \\
& Classes' objective: Helping students & Classes' objective: Delivering content \\
\hline Peers & & $\begin{array}{l}\text { Peers' disapproval } \\
\text { Social image in front of peers }\end{array}$ \\
& & Negative disposition to interact \\
\hline Teacher & Positive disposition to interact & $\begin{array}{l}\text { Large gap between teachers' and students' } \\
\text { levels of experience and knowledge }\end{array}$ \\
& $\begin{array}{l}\text { Small gap between teachers' and students' } \\
\text { levels of experience and knowledge }\end{array}$ & \\
\hline
\end{tabular}

Regarding student factors, some participants mentioned the relevance of preparedness and confidence in their abilities and knowledge to interact with teachers, for example, preparing material and readings to talk and ask questions. Students that felt less academically prepared were less likely to interact with tutors and lecturers, particularly in classrooms, in 
comparison with students that felt prepared. On the other hand, students with higher levels of confidence in the content and personal communication abilities reported having more interactions with tutors and lecturers than students with lower levels of confidence. Both levels of preparedness and confidence have been mentioned in the literature as key factors that influence teacher and student interactions in classrooms (Fassinger, 1995).

For some participants, it was necessary to feel prepared and confident in their abilities and knowledge to interact with teachers, especially considering that most of the interactions were academic related. It could suggest that for some students, the adjustment to a new academic context was related with being informed of certain requirements to interact and that their abilities were constantly evaluated. Table 4.6 presents two participants' views about the influence of levels of preparedness and confidence on interactions with teachers.

Table 4.6 Student factors and their influences on teacher-student interactions

\begin{tabular}{lll}
\hline \multicolumn{1}{c}{ Factors } & \multicolumn{1}{c}{ Students' quotes } \\
\hline Facilitator & $\begin{array}{l}\text { High levels of } \\
\text { preparedness and } \\
\text { confidence }\end{array}$ & $\begin{array}{l}\text { I feel like I do that [interact with teachers] when there's something } \\
\text { well prepared maybe that's something that passes from older } \\
\text { people, like my seniors, and they always tell me like if you go to } \\
\text { see somebody, you got to be prepared (I15, BA_6). }\end{array}$ \\
Barrier & $\begin{array}{l}\text { Low levels of } \\
\text { preparedness and } \\
\text { confidence }\end{array}$ & $\begin{array}{l}\text { "I think if people aren't confident in the material, if they haven't } \\
\text { read enough of the lecture or more commonly they haven't done } \\
\text { the readings, then people won't want to speak" (I2, BA_2). }\end{array}$
\end{tabular}

Regarding institutional factors, classroom size was the most common aspect mentioned. More than three quarters of participants noted that large classes impeded the interactions with lecturers. Students argued that usually in lecturers there was limited time to interact and participate in discussions. This aspect also has been mentioned by Fassinger (1995) and Weaver and Qi (2005) who indicate that teaching strategies in large lectures tend mainly to focus on teachers' discourse instead of encouraging students' participation. On the other hand, students noted that small classrooms sizes facilitated the interactions with teachers. The majority of participants considered that tutorials were small classrooms when they had more opportunities to talk to their teachers.

Additionally, students' views about the objectives of classes influenced their decision to interact with teachers. Most of the interviewees stated that the role of tutors was to help students with academic issues answering questions and facilitating learning of the content. 
Students that shared this perception were more likely to feel comfortable interacting with tutors and seeking their help with any academic issue.

On the other hand, there was a perception among students that in lectures, teachers should deliver difficult content to a large group of students within a limited time not having space to interact with particular students. Because participants considered that the content of lectures was challenging, almost all participants preferred paying full attention to lecturers rather than having interruptions with any strategy to encourage participation. In the case of specific questions for lecturers, the majority of students often reported waiting until the end of classes to ask. It seems that students' preconceptions of teaching strategies in particular classes are associated with their behaviours in those settings (Pascarella, 1980; Tinto, 1993). For instance, students' preconception of lectures, as a setting to listen and learn content, hindered their decision to interact with lecturers during classes. Table 4.7 exemplifies the influences of the institutional factors mentioned above with students' quotes.

Table 4.7 Institutional factors and their influences on teacher-student interactions

\begin{tabular}{|c|c|c|}
\hline & Factors & Students' quotes \\
\hline \multirow[t]{2}{*}{ Facilitators } & $\begin{array}{l}\text { Small classroom } \\
\text { size }\end{array}$ & $\begin{array}{l}\text { "Probably mostly come down to the size of the group, if there's } \\
\text { smaller group, they're gonna be able to help you more, dedicated } \\
\text { more time to you, to your problems than a big group" (I6, BS_2). }\end{array}$ \\
\hline & $\begin{array}{l}\text { Classes' } \\
\text { objective: helping } \\
\text { students }\end{array}$ & $\begin{array}{l}\text { "I guess tutors seem to be more of the support role }[\ldots] \text { is kind of } \\
\text { natural, is part of tutorials to actually talk to them" (I8, BA_5). }\end{array}$ \\
\hline \multirow[t]{2}{*}{ Barriers } & $\begin{array}{l}\text { Large classroom } \\
\text { size }\end{array}$ & $\begin{array}{l}\text { "First year lectures are so big, it's like } 200 \text { or } 300 \text { people in every } \\
\text { lecture, so it's not possible to interact more with the lecturers } \\
\text { during the lecture" (I9, BS_3). }\end{array}$ \\
\hline & $\begin{array}{l}\text { Classes' } \\
\text { objective: } \\
\text { delivering content }\end{array}$ & $\begin{array}{l}\text { "In lectures, it's mostly you're listening and lecturers're talking" } \\
\text { (I16, BB_1). }\end{array}$ \\
\hline
\end{tabular}

In the present research, peers' disapproval and social image were considered two barriers for teacher and student interactions in the first year. More than half of participants shared the perception that there were some classrooms settings where was inappropriate to interact, for example in lectures and others where was appropriate such as tutorials. Pascarella (1980) indicated that peers usually share a culture of interactions with rules, often implicit, that determine contexts where it is appropriated to interact with teachers. If students 
break some of these implicit rules, as in any social group, they could receive peers' disapproval that may influence being accepted or rejected in a particular group (Fassinger, 1995; Weaver \& Qi, 2005). In the present study, some participants named these rules as 'subtle communication' as seen in Table 4.8.

In lectures, some participants considered inconvenient to interact with teachers because individual questions could disrupt other classmates who were also learning in classes. Another reason was that participants were afraid of being seen as unintelligent in front of hundreds of peers and therefore, participants preferred to avoid the interactions with lecturers in classes. Fears of interrupting others and being seeing as unintelligent were barriers to interact with lecturers that also have been mentioned in the literature (Weaver \& Qi, 2005). These obstacles could influence the social acceptation among peers that is important for first year students (Fassinger, 1995; Weaver \& Qi, 2005).

In contrast, interacting with tutors in classes was considered appropriate; tutorials were the place to interact. More than three quarters of participants reported that in tutorials they had recurrent opportunities to ask personal questions to tutors that reduced the potential embarrassment in front of peers. Table 4.8 shows two key students' examples of how peers' disapproval and approval, and social image hindered teacher-student interactions.

Table 4.8 Peers factors and their influences on teacher-student interactions

\begin{tabular}{lll}
\hline \multicolumn{1}{c}{ Factors } & \multicolumn{1}{c}{ Students' quotes } \\
\hline Barriers & $\begin{array}{l}\text { Peers' } \\
\text { disapproval }\end{array}$ & $\begin{array}{l}\text { They'll [peers] be like "if you have a question, ask him later" 'cause } \\
\text { that was going to do they too, it's like a general subtle communication } \\
\text { understanding that all students have among each other that if you do } \\
\text { have a question, if it is a stupid question then they will laugh at you in } \\
\text { the middle of the class and they'll be like "why are you distracting our } \\
\text { studying experience?" (I14, BS_9). }\end{array}$ \\
& $\begin{array}{l}\text { Social image } \\
\text { in front of } \\
\text { peers }\end{array}$ & $\begin{array}{l}\text { "Students don't want to be wrong in front of everyone else, I think } \\
\text { most of the content is quite difficult, so most people are unsure the } \\
\text { answers, so they don't want to answer in case is wrong" (I12, BS_7). }\end{array}$ \\
Facilitators & $\begin{array}{l}\text { Peers' } \\
\text { approval }\end{array}$ & $\begin{array}{l}\text { [Asking] some your specific questions in lecturers is a waste of others } \\
\text { time [...] sometimes are stupid questions [...] you should ask in } \\
\text { tutorials or by email (I2, BC_1). }\end{array}$ \\
\hline
\end{tabular}

Regarding the teacher category, two factors were mentioned teachers' disposition to interact and the gap between teachers and students' levels of knowledge and experience. The first aspect, teachers' disposition to interact, was the second most frequently mentioned factor. More than half of students reported that some teachers' verbal and nonverbal 
behaviours and attitudes during classrooms showed their disposition and availability to interact with students. Teachers who were perceived as having a positive disposition to interact expressed verbally and nonverbally their availability to answer questions in and outside classrooms, showed interest in connecting with students and understood their learning needs. Examples of these positive behaviours were smiling to students, showing a sense of humour and being relaxed during classes. More than half of participants emphasised that they preferred to interact with teachers that showed a positive disposition in classes. Evidence analysed in the literature review suggests that verbal and nonverbal communication could influence the frequency of teacher and student interactions (Moore \& Masterson, 1996; Pascarella, 1980; Wilson et al., 1974)

On the other hand, some participants reported that few teachers presented a negative disposition to interact. According to students, some of these teachers did not show positive verbal, and nonverbal communication and others usually showed negative attitudes during classes that were interpreted as unapproachability, unavailability to interact and a lack of understanding of students' learning needs. For instance, students interpreted teachers' disinterest to interact with students when teachers arrived late to classes and showed urgency to leave after class. When participants perceived teachers' negative behaviours and attitudes in classes, they were more reluctant to interact with those teachers afterwards, as seen in Table 4.10. In brief, whereas teachers' positive disposition to interact facilitated the interactions, showing a negative disposition impeded the interactions as Moore and Masterson (1996) also indicated.

The second teacher related factor was the gap between teachers' and students' levels of experience and knowledge. Some students considered that levels of formality in the interactions and understanding of students' needs varied among teachers with different levels of experience and knowledge. Some participants mentioned that when there was a small gap between them and their teachers' level of experience and knowledge, teachers could easily sympathise with the students' academic experience in a particular subject because they were students of the same subject a few years before. Besides, participants felt that interactions with these teachers were often more informal than with highly experienced teachers, for example, lecturers, facilitating help-seeking and a comfortable and easy communication. Table 4.9 and Table 4.10 present representative students' views of how teachers' disposition and the gap between teachers and students facilitated and hindered the interactions. 
Table 4.9 Teacher factors that facilitated teacher-student interactions

\begin{tabular}{lll}
\hline \multicolumn{1}{c}{ Factors } & \multicolumn{1}{c}{ Students' quotes } \\
\hline Facilitators & $\begin{array}{l}\text { Positive disposition to } \\
\text { interact }\end{array}$ & $\begin{array}{l}\text { All lecturers that I had, which would be five or so, have } \\
\text { always said if you have any question you can speak to me } \\
\text { after class and they ask questions even we don't replay } \\
\text { during the class, and they all seem very friendly and welcome } \\
\text { to any discussion (I2, BA_2) }\end{array}$ \\
$\begin{array}{l}\text { Small gap between } \\
\text { teachers and students' } \\
\text { levels of experience and } \\
\text { knowledge }\end{array}$ & $\begin{array}{l}\text { Usually, tutors are like just few years older than me, they } \\
\text { know how to learn, the problem they faced doing it, while the } \\
\text { lecturers some of the course will be the sake of nature to } \\
\text { them, they don't realise why I don't understand something, } \\
\text { but the tutors will (I12, BS_7). }\end{array}$ \\
&
\end{tabular}

Table 4.10 Teacher factors that hindered teacher-student interactions

\begin{tabular}{lll}
\hline \multicolumn{1}{c}{ Factors } & \multicolumn{1}{c}{ Students' quotes } \\
\hline Barriers & $\begin{array}{l}\text { Negative disposition } \\
\text { to interact }\end{array}$ & $\begin{array}{l}\text { You don't want to talk to her (tutor) because if you go and ask } \\
\text { her questions, she is like not happy to answer questions and can't } \\
\text { explaining properly. She (tutor) comes late to class every time, } \\
\text { and she's quite grumpy, she's like "Oh, you should know this, } \\
\text { shouldn't you know this by now?", she was always kind of } \\
\text { condescending [...] I don't ask her questions anymore because } \\
\text { I'm not very good at the subject, and she's just condescending } \\
\text { making me feel upset (I13, BS_8). }\end{array}$ \\
& $\begin{array}{l}\text { Large gap between } \\
\text { teachers and } \\
\text { students' levels of } \\
\text { experience and } \\
\text { knowledge }\end{array}$ & $\begin{array}{l}\text { experience is different, the way we are thinking is different, and } \\
\text { sometimes you ask some questions, and they just don't get it, } \\
\text { and they just talk to you what is this thing and then repeat and } \\
\text { repeat (I17, BS_5). }\end{array}$ \\
\hline
\end{tabular}

It can be argued that all factors that facilitated and hindered teacher-student interactions were related to each other. For instance, students that felt less prepared and confident with their content knowledge would be more likely to interact with teachers in small classes. In this type of classes, students could have individual attention from teachers that showed their willingness to interact and not being exposed to public embarrassment in front of their peers. 


\subsubsection{Quality of teacher-student interactions.}

When participants evaluated the quality of the interactions, their answers considered two dimensions: affective and academic. The affective dimension coincided with some of the characteristics of positive interactions mentioned in the literature review including trust, intimacy, care and support (Cokley et al., 2004; Dobransky \& Frymier, 2004; Hagenauer \& Volet, 2014). The academic dimension was related to the educational benefits that students perceived of the interactions with teachers, especially, of those interactions with an academic purpose. Considering both dimensions, over three quarters of participants evaluated most of their interactions with teachers in the first year as positive and helpful.

Regarding participants' views, positive and helpful interactions can be defined as close, caring, and supportive interactions in which teachers know students in personal and academic terms, students feel comfortable to interact with teachers, and teachers are interested and facilitate students' learning and personal growth. This definition includes three aspects. The first one refers to the closeness of the interactions, particularly knowing students at academic and personal level. Most of the interviewees described close and intimate interactions when teachers knew their names and learning progress. The second aspect of positive interactions refers to students feeling comfortable to interact with teachers. Most of the participants who had positive interactions with teachers felt understood, accepted (not being judged), supported and encouraged to seek help in case they needed it.

Finally, the third aspect is related to the academic dimension and consists of facilitating students' learning and personal growth. When describing positive teacher-student interactions, participants mentioned that tutors and lecturers actively heard their inquiries paying attention to their needs, and gave useful and thoughtful answers to their questions promoting their learning in the subjects. Table 4.11 presents examples of the three components of positive and helpful teacher-student interactions mentioned above. 
Table 4.11 Characteristics of positive and helpful teacher-student interactions

\begin{tabular}{|c|c|c|c|}
\hline Dimension & Characteristics & Description & Students' quotes \\
\hline Affective & Closeness & $\begin{array}{l}\text { Teachers know } \\
\text { students at personal } \\
\text { and academic level. } \\
\text { Teachers and } \\
\text { students have } \\
\text { regular interactions. }\end{array}$ & $\begin{array}{l}\text { "The tutors know my name and } \\
\text { everything they can keep track on my } \\
\text { progress, they can see how it is from } \\
\text { week } 1 \text { to week } 12 \text {, I think that's the } \\
\text { difference there" (I15, BA_7). }\end{array}$ \\
\hline $\begin{array}{l}\text { Affective } \\
\text { and } \\
\text { academic }\end{array}$ & Care and support & $\begin{array}{l}\text { Students feel } \\
\text { understood, } \\
\text { supported and } \\
\text { encouraged to } \\
\text { interact with their } \\
\text { teachers. }\end{array}$ & $\begin{array}{l}\text { "The tutors are more friendly, so you } \\
\text { know you're not being judged if you ask } \\
\text { them a few questions whatever you say } \\
\text { they keep their smile and they always } \\
\text { give feedback after the question what you } \\
\text { need to do" (I9, BS_3). }\end{array}$ \\
\hline Academic & $\begin{array}{l}\text { Facilitating } \\
\text { students' learning } \\
\text { and personal } \\
\text { growth }\end{array}$ & $\begin{array}{l}\text { Teachers understand } \\
\text { students' needs and } \\
\text { give particular and } \\
\text { thoughtful responses } \\
\text { to their inquiries. }\end{array}$ & $\begin{array}{l}\text { I think there was once where they } \\
\text { (teachers) answer the questions it's not } \\
\text { just "this is what you have to do for this } \\
\text { question". It's more like why is like [...] } \\
\text { I felt like this helped me to understand } \\
\text { more fully and also I felt I was listened } \\
\text { too as well because if I had questions, } \\
\text { they would've answered me seriously and } \\
\text { consider more just than whatever } \\
\text { question I had, they give me back } \\
\text { information as well (I8, BA_5). }\end{array}$ \\
\hline
\end{tabular}

On the other hand, when students asked about negative teacher and student interactions, all interviewees mentioned having at least one negative and unhelpful interaction with their teachers in the first year. Regarding participants' descriptions, negative and unhelpful interactions can be defined as distant interactions where teachers show disinterest and lack of knowledge of students' personal and academic characteristics having little or no effect on students' learning and personal growth. As seen in this description, when participants described negative and helpful interactions, they used affective and academic dimensions. Table 4.12 exemplifies the three aspects of negative/unhelpful interactions: distant interactions, disinterest and lack of knowledge of students at the personal and academic level, and having minimal or no impact on students' learning. 
Table 4.12 Characteristics of negative and unhelpful teacher-student interactions

\begin{tabular}{|c|c|c|c|}
\hline Dimension & Characteristics & Description & Students' quotes \\
\hline Affective & $\begin{array}{l}\text { Distance in the } \\
\text { interactions }\end{array}$ & $\begin{array}{l}\text { Interactions are } \\
\text { infrequent. Teachers } \\
\text { and students make } \\
\text { limited and failed } \\
\text { attempts to interact. }\end{array}$ & $\begin{array}{l}\text { Lecturers definitely feel more distant } \\
\text { because there is a whole lecture fill } \\
\text { with people and we only see them once } \\
\text { a week sometimes twice a week, and } \\
\text { that's it [...] occasionally they draw } \\
\text { questions, but I don't feel I want to } \\
\text { answer it, maybe because of the } \\
\text { situation, there's so many people, and } \\
\text { it feels like he's not directing the } \\
\text { question to me, he's directing the } \\
\text { question to the whole room, so I just } \\
\text { feel the distance (I15, BA_7). }\end{array}$ \\
\hline $\begin{array}{l}\text { Affective } \\
\text { and } \\
\text { academic }\end{array}$ & $\begin{array}{l}\text { Disinterest and lack } \\
\text { of knowledge }\end{array}$ & $\begin{array}{l}\text { Teachers have little o } \\
\text { no knowledge of } \\
\text { students at personal } \\
\text { and academic level. } \\
\text { Students usually do } \\
\text { not know their } \\
\text { teachers personally. }\end{array}$ & $\begin{array}{l}\text { "A lot of my lecturers nearly all of } \\
\text { them, I don't think they knew who I } \\
\text { was like you know I was part of the } \\
\text { cohort" (I6, BS_2). } \\
\text { "You don't even know your lecturers } \\
\text { most of the time you wouldn't even } \\
\text { like speak to them one on one" (I4, } \\
\text { BA_3). }\end{array}$ \\
\hline Academic & $\begin{array}{l}\text { Having little or no } \\
\text { impact on students' } \\
\text { learning and } \\
\text { personal growth }\end{array}$ & $\begin{array}{l}\text { Teachers have little or } \\
\text { no knowledge of } \\
\text { students' needs giving } \\
\text { superfluous answers } \\
\text { and feedback to } \\
\text { students' inquiries. }\end{array}$ & $\begin{array}{l}\text { Not all tutors did a good job because I } \\
\text { got different feedback from different } \\
\text { tutors, you really get different } \\
\text { feedback, and they won't track your } \\
\text { previous behaviour, so they just give } \\
\text { you feedback this time and don't with } \\
\text { the previous behaviour, so you don't } \\
\text { see if you improved it or not (I17, } \\
\text { BS_6). }\end{array}$ \\
\hline
\end{tabular}

Regarding the affective dimension, participants felt that teachers showed disinterest to interact. Teachers made limited and failed attempts to interact with students, and some of these attempts were directed to the whole group rather than to individual students feeling the distance in the contact. For example, a failed interaction was when lecturers asked questions to the audience, but there was no answer from students. Because of the distance in the interactions, students noted that teachers did not know them at a personal level, for example, participants felt that teachers showed little interest in knowing students' names and speaking individually to them.

When students described unhelpful interactions, they showed concern about the lack of positive academic outcomes of these interactions. The majority of students reported that when they had negative and unhelpful interactions with teachers, teachers had little or lack of 
knowledge of students' particular academic performance giving superfluous feedback and confusing answers to their inquiries. Participants emphasised that these answers had insignificant or no impact on their learning and personal growth.

\subsection{Benefits of Positive Teacher-Student Interactions}

As mentioned above, students evaluated the quality of their interactions with teachers regarding two dimensions: affective and academic. The majority of participants agreed that most of the interactions with teachers in the first year were positive and helpful improving their motivation, engagement and, consequently, their learning on the subject.

Regarding motivation, as seen in Table 4.13, students mentioned two concepts related to intrinsic motivation, confidence and support (Ryan \& Deci, 2000). More than a half of participants reported that when teachers helped them to resolve questions, they felt more confident in addressing other similar issues on their own increasing their motivation in the subject. Also, participants who had positive interactions with tutors felt supported by teachers; they could seek their help when need it. This teachers' support was a key factor to motivate students to achieve learning outcomes and obtain high marks in assessments in the subject that influenced their engagement in a particular subject. Table 4.13 presents the most representative students' views about the benefits of positive interactions for motivation and engagement.

Table 4.13 Influences of teacher-student interactions on motivation and engagement

\begin{tabular}{cll}
\hline \multicolumn{1}{c}{ Areas } & \multicolumn{1}{c}{$\begin{array}{c}\text { Main } \\
\text { components }\end{array}$} & \multicolumn{1}{c}{ Students' quotes } \\
\hline Motivation & $\begin{array}{l}\text { Feeling } \\
\text { confident }\end{array}$ & $\begin{array}{l}\text { "A question that is really intimidating, they can break it out and } \\
\text { help me through until actually, I can do it by myself. They make } \\
\text { me more confident in tackling stuff" (I12, BS_7). } \\
\text { "I'm not a very motivated person myself, so I think having more } \\
\text { Engagement }\end{array}$ \\
\cline { 2 - 3 } & $\begin{array}{l}\text { Feeling } \\
\text { supported } \\
\text { contact with the staff, I have more chance to ask any question that I } \\
\text { had, and I felt I was supported throughout the year" (I8, BA_5). } \\
\text { Doing academic } \\
\text { work/activities }\end{array}$ & $\begin{array}{l}\text { Some tutors I really look forward to doing the readings, thinking } \\
\text { about stuff going to the class and discussing those ideas and it is } \\
\text { motivating to say "okay, in order to have these really good } \\
\text { discussions I have to go to lectures, do the work, do the readings" } \\
\text { (I2, BA_2). }\end{array}$
\end{tabular}


Seeking teachers The tutors that are more successful are the ones they have a to interact

following of students, because they work really hard and explaining concepts to students, making sure students actually understand what they're doing [...] those are the ones like students would be like "Oh, definitely I want to come to your class, what other class are you teaching?, I'm going to come to it" those are the really good tutors that would motivate you to actually go to the tuts and actually do the work (I10, BS_4).

On the other hand, some participants, particularly the oldest in the group, mentioned that motivation was related to their own goals and interests perceiving that interactions with teachers had little or no impact on their levels of motivation. This could be linked to students' perceptions of their levels of self-regulation and self-efficacy in the university. An example of this perception is the following student's quote that also compares university with the high school context:

I mean they're [tutors and lecturers] doing a little bit but it's not like they were in school, so you have to really be motivated yourself, [...] I just learned in uni it's not down to the lecturers and tutors to motivate you, you have to do it yourself (I6, BS_2).

As seen in Table 4.13, positive teacher-student interactions also encouraged students' engagement in their academic activities. The majority of participants mentioned that positive interactions with teachers engaged them to spend time and energy studying, doing homework, reading, and interacting actively with teachers in and out of classrooms. Students perceived that their engagement in the subject was related to their motivation. More than half of participants mentioned that when they felt motivated, they also felt more engaged to do academic activities, for instance, homework, which also reinforced their motivation with the subject. The following student explains the connection between feeling supported and motivated and their engagement in educational activities:

"When you know there's someone else besides you that understand the subject and can help you, it makes easier and makes me feel that I want to study that subject more" (I14, BS_9).

Participants who reported positive interactions with teachers felt motivated and engaged with the subject that also influenced their learning. The most common purpose of the interactions was academic showing the importance of teacher-student interactions for 
learning in higher education, as other researchers have stated (Kim \& Lundberg, 2016; Kim \& Sax, 2014; Pascarella, 1985). Students that had positive interactions with teachers felt motivated and supported, spent time and resources in their academic activities, challenged themselves to enhance their academic goals and perceived that their learning was improving in that particular subject. For instance, half of participants mentioned that positive interactions facilitated a deeper understanding of the subject's content. Table 4.14 illustrates the benefits of positive interactions for learning with two students' examples

Table 4.14 Influences of teacher-student interactions on learning

\begin{tabular}{lll}
\hline Area & \multicolumn{1}{c}{$\begin{array}{c}\text { Main } \\
\text { components }\end{array}$} & \multicolumn{1}{c}{ Students' quotes } \\
\hline Learning & $\begin{array}{l}\text { Understanding } \\
\text { the content }\end{array}$ & $\begin{array}{l}\text { If I ask a question and they (teachers) answer it well, it's a lot easier } \\
\text { to learn that way because it helps to understand it, it helps to } \\
\text { understand the concepts better, and it helps you to retain the } \\
\text { knowledge as well, because I've found that I learned really well when } \\
\text { I'm talking to another people, and we discuss the stuff (I16, BB_1). }\end{array}$ \\
& $\begin{array}{l}\text { Learning how to } \\
\text { write assignments }\end{array}$ & $\begin{array}{l}\text { I had a history unit in my first year, and I've never done history } \\
\text { before, so [...] I think I went to his (tutor) office hours twice in that } \\
\text { semester and we worked in sources that I could use to reference } \\
\text { whatever I was trying to say in the essay, so that was pretty good, } \\
\text { 'cause I got a lot of one on one interaction, and actually write my } \\
\text { essay because history wasn't my strong point (I7, BA_4). }\end{array}$ \\
\hline
\end{tabular}

Additionally, some participants described the connection between frequent positive teacher-student interactions, dedicating time to academic activities and having learning outcomes influencing their academic performance in a particular subject, as this student describes:

"The subjects that I have more interaction I did better" (I8, BA_5).

In brief, the majority of participants mentioned that having positive interactions with their teachers helped them to feel motivated and engaged, facilitating their learning on the subject, especially about the content and assessments criteria. Figure 4.1 presents a diagram to represent participants' perceptions of how positive interactions with teachers benefited motivation, engagement and learning in subjects, the relationship between these benefits and how positive learning outcomes reinforced having positive interactions with teachers. 
Figure 4.1 Preliminary diagram of benefits of positive teacher-student interactions

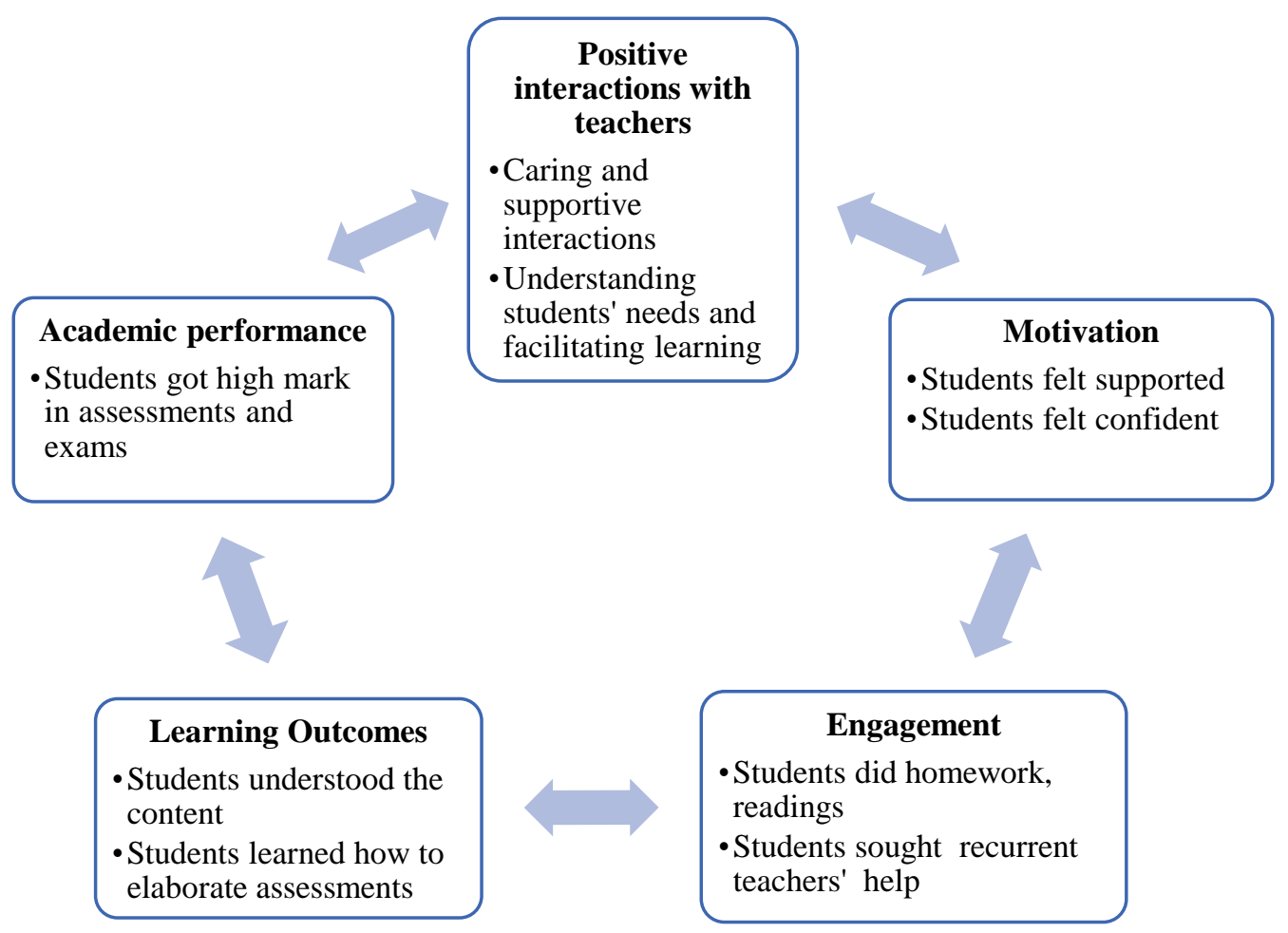

Regarding a sense of belonging to the institution, more than half of participants considered that teacher-student interactions were not related to feeling part of the university. Because the university studied was a large institution, participants felt that interactions with teachers were a small part of the whole institution and most of them did not feel part of the university yet. According to participants, to develop a sense of belonging to the university, first year students should meet staff and peers by joining extra-curricular activities in the university, for example, clubs and societies. Meeting staff and peers would facilitate the social integration to the university and feeling part of this institution. The following student explains this view:

"If you wanna be part of the university, then you kind of have to make that effort, joining groups, make friends, going to the camps and make friends, that's the only way to really feel part of the university" (I10, BS_4).

Despite the lack of connection with the universities, half of participants noted that positive interactions with their teachers helped them to feel part of their subjects and faculty. For example, the following student describes: 
"I feel close with the subjects and with my major, but I don't think that I feel as closely connected with the uni" (I2, BC_1).

Participants' sense of belonging to classes could be understood as the beginning of the process of affiliation to the university stated by Lizzio (2006), and it could improve motivation and engagement with that particular subject (Freeman et al., 2007; Lizzio, 2006; Tinto, 1993).

Moreover, some students found that positive interactions with teachers helped them to develop social and communication skills, particularly feeling confident to speak and interact with others and practising English. This last aspect was relevant for the group of international students. For most of the participants who spoke English as a second language, teachers were the first people that they met in the university and the interactions with teachers helped their adaptation to the university through the development of social and communicational skills. Table 4.15 shows the students' main views about the sense of belonging to the university and social/communication skills related to positive teacher-student interactions.

Table 4.15 Sense of belonging to the university and social/communication skills

\begin{tabular}{lll}
\hline \multicolumn{1}{c}{ Area } & \multicolumn{1}{c}{ Component } & \multicolumn{1}{c}{ Students' quotes } \\
\hline $\begin{array}{l}\text { Sense of belonging } \\
\text { to the university }\end{array}$ & $\begin{array}{l}\text { "I think just to communicate with tutors and lecturers not } \\
\text { help me to be close and connected with the uni" (I2, BC_1). } \\
\begin{array}{l}\text { Sommunication } \\
\text { skills }\end{array}\end{array}$ & $\begin{array}{l}\text { They [interactions with teachers] helped me be more } \\
\text { confident socialising because if I can speak to a tutor or } \\
\text { lecturer who has nothing to do with me apart from the class, } \\
\text { I can also speak to another people and I think university in } \\
\text { general (I8, BA_5). }\end{array}$ \\
\cline { 2 - 3 } & $\begin{array}{l}\text { Communication } \\
\text { skills }\end{array}$ & $\begin{array}{l}\text { Because we don't have so many opportunities to interact } \\
\text { with the local people and then you talk to the lecturers face } \\
\text { to face, you would feel more confident next time you meet } \\
\text { local people because you know more about the customs and } \\
\text { language (I17, BS_5). }\end{array}$ \\
&
\end{tabular}

Finally, another reported benefit is the influence that positive teacher and student interactions had on future interactions. Participants who had experienced positive interactions with teachers in the first semester were more likely to seek more interactions with teachers in the following semesters. This could lead to having close and positive interactions in the senior years as other studies have found (Fuentes, Ruiz Alvarado, Berdan, \& DeAngelo, 
2014). For instance, the following student explains her view about the consequences of having positive interactions with teachers:

"If you have good experiences then you want to approach them [teachers] more and seek out that help rather than if you have negative experiences, you being more reluctant to approach your tutor or approach your lecturer" (I3, BS_1).

\subsection{Conclusion}

This chapter has discussed five main findings. First, the majority of participants expected to have limited interactions with their lecturers in the first year but frequent and close interactions with their tutors. For most of the students, their experiences coincided with their expectations about interactions with lecturers, but not completely with tutors. Some students considered that interactions with tutors were less frequent and close that they thought they would be.

Second, the majority of the interactions between teachers and students had an academic purpose and occurred inside classrooms. Some participants reported interacting with teachers outside classrooms through consultation hours and emails. The third finding was that class size and teachers' disposition to interact were key factors that influence the frequency and quality of interactions.

Fourth, participants assessed the quality of interactions based on two dimensions: affective and academic. Participants evaluated that positive interactions were close and helpful for their learning. In contrast, negative and unhelpful interactions were distant interactions where teachers' help had little or no impact on students' learning. Finally, the majority of students reported that positive interactions with teachers had educational benefits, especially for motivation, engagement and learning. For most students, a sense of belonging to the university was not related to the interactions with teachers. 


\section{Chapter 5 Discussion and Conclusions}

This chapter discusses key findings from the present study on teacher and student interactions and their main implications for the first year experience. This chapter consists of five sections. The first section examines main implications regarding the frequency and quality of teacher and student interactions. The second section discusses the main consequences of the benefits of positive teacher and student interactions. The third section consists of an analysis of the limitations of this study regarding participants and research methods and suggestions for further qualitative research on teacher and student interactions. Then, the fourth section presents two recommendations for higher education institutions for the first year inductions programs and professional development of teaching staff. Finally, this chapter ends with a conclusion about the principal contribution of this study for higher education institutions.

\subsection{Teacher-Student Interactions in the First Year}

There are two significant findings of teacher and student interactions in the first year of university. The first one is related to the limited teacher and student interactions and the second is related to the affective dimension of the quality of interactions.

\subsubsection{Frequency of teacher-student interactions in the first year.}

This study shows that first year students have limited interactions with their lecturers and slightly frequent interactions with tutors even though that frequency does not meet their expectations. Although these findings are similar to other qualitative studies with undergraduate students (Chan et al., 2017; Cotten \& Wilson, 2006; Zhang et al., 2015), they reveal a concerning aspect of the educational experience of undergraduate students in the first year of university. As such, teacher and student interactions are not as common as students expect and as empirical research on the topic recommends (Chickering \& Gamson, 1991).

A vast body of research in the first year experience reports the key role that academic staff plays in the adjustment, academic performance and satisfaction with the educational experience of undergraduate students, through the interactions (Chickering \& Gamson, 1991; Pascarella \& Terenzini, 1991; Tinto, 1993). Additionally, many empirical studies show the benefits of teacher-student interactions for learning, academic performance and social 
integration of students (Lizzio, 2006; Pascarella \& Terenzini, 1991; Tinto, 1993). In this context, it can be problematic for students that the interactions with teachers in the first year are not frequently enough, particularly in classrooms settings, where students spend most of the time with teachers.

One possible explanation of this frequency of teacher-student interactions is classroom size. Along with other qualitative studies, this present study shows that large classrooms hinder the interactions with lecturers whereas small classrooms of tutorials facilitate the interactions between tutors and students (Chan et al., 2017; Cotten \& Wilson, 2006; Hurtado et al., 2011; Zhang et al., 2015). However, in the actual context of higher education, large classrooms have become necessary to respond to the large demand of students entering universities, particularly in Australia. According to the Organization for Economic Cooperation and Development (OECD) (2016), Australia is one of the countries with highest entry rates of students who finished high school on undergraduate degrees in comparison with other OECD countries. Considering that large classroom size is a relatively stable characteristic of the educational system, it is necessary to examine alternatives to promote teacher and student interactions beyond classrooms settings, for example, facilitating interactions outside classrooms.

Beattie and Thiele (2016) have argued that large classes can be a facilitator of interactions outside classrooms. In their research, Beattie and Thiele (2016) reported that students had few interactions with lecturers in classes, but they frequently sought their teachers outside classrooms to resolve academic issues. Other studies such as Kuh et al. (2010) and Pascarella and Terenzini (1991) have evaluated the frequency of teacher-student interactions outside classrooms concluding about their relevance for students' academic performance. In fact, the present research shows that interactions outside classrooms through consultation hours and email are useful for asking individual academic questions. Considering the limited interactions inside classrooms and the benefits of interactions out of classrooms, teacher-student interactions outside classrooms seem an effective alternative to facilitate interactions in contexts with large classes.

On the other hand, small classroom size, such as tutorials, facilitates teacher and student interactions in the first year. Coinciding with other researchers, this finding sheds light on the role that tutors play in the interactions with students. Some empirical studies indicate that in the first year, tutors are usually students' first option for seeking academic help (Cox, Zhu, Cekic, Chavela \& London, 2010; Walsh, Larsen \& Parry, 2009). Retna, Chong and Cavana (2009) indicate that tutors in small groups could develop different 
strategies for encouraging discussion and feedback, especially in comparison with classes with large groups of students. It implies that tutors have many opportunities to create a supportive and constructive environment in their classes that promote positive interactions with their students.

\subsubsection{The affective dimension of the quality of teacher-student interactions.}

This study reveals that the quality of teacher and student interactions is not only determined by the academic benefits obtained but also depends on affective and relational components. In fact, having close, caring and supportive interactions are key to define positive interactions with teachers. This finding suggests that the emotional aspects of interactions are significant for the first year of university. These findings coincide with some

components of the "deskside manner framework" regarding the relevance of staff showing respect, being empathetic and honest that benefit their academic success (Fleischman \& Imaz-Marial, 2015).

Why should academic staff be interested in promoting close, caring and supportive interactions with first year students? One reason is that affective components of the interactions are central to establish foundations for positive relationships (Hagenauer \& Volet, 2014). According to Hagenauer and Volet (2014), the affective dimension of teacher and student interactions is "the bond built between students and teachers, forming the basis for secure and affective positively experienced relationships" (p.374). Developing close, caring and supportive interactions could imply that students trust their teachers feeling comfortable to ask questions, commit mistakes and receive feedback that ultimately, encourage their learning. For example, Dobransky (2004) found that students who had interactions with teachers characterised by trust and intimacy were more likely to improve their learning outcomes.

However, research on faculty and student interactions in higher education has paid little attention to the affective components of the interactions. Instead, the research has focused on the academic aspects. Large-scale studies such as Pascarella and Terenzini (1991) and Kuh et al. (2010) have shown strong evidence of the benefits of interactions with an educational purpose for students' academic performance and motivation. Based on that evidence, some researchers have argued that the most valuable aspects of teacher-student interactions are teachers' help to resolve academic issues and provide feedback (Kuh et al., 2010; Pascarella \& Terenzini, 1991). According to these researchers, higher education 
institutions should promote teacher-student interactions with a focus on educational aspects. The findings of the present research support this argument; the academic dimension is relevant for the interactions. However, focusing just on the academic could overlook the relevance of the emotional components of the interactions in the first year that can constitute the basis to have beneficial teacher-student interactions for academic outcomes.

Perhaps, the transition process can explain the significance of the emotional components of interactions in the first year of university. The majority of first year students are transitioning directly from high school where they often experience close and caring interactions with their high school teachers. It suggests that first year students could need to experience caring and close interactions with their teachers as a facilitator of the transition to higher education. In fact, Bowden (2013) evaluated the perceptions of first year students about their experiences at an Australian university. This study found that emotional components of the interaction with teachers helped students to develop a bond with teachers that facilitated students' confidence, self-identity and social integration in the first year (Bowden, 2013). Bowden (2013) indicates that developing a bond based on close and caring interactions helped first year students to feel connected to the university reducing feelings of anxiety and stress.

Similarly, some transition researchers have argued that warmth and positive interactions with faculty promote students' feelings of comfort, acceptance and belonging to a new and challenging context, which are essential for the transition of first year students (Lizzio ,2006; Pascarella and Terenzini,1991; Tinto,1993). It could imply that the emotional components of teacher-student interactions are fundamental to the first year experience in universities.

How can teachers promote close, caring and supportive interactions? A possible method is showing a positive disposition to interact with students. As found in this study, teachers' positive verbal and nonverbal communication facilitates the interactions with students, for example, expressing their availability to meet students outside classrooms and smiling. Research on teaching and communication has indicated that positive teachers' behaviours and attitudes are associated with characteristics including availability, approachability, closeness and immediacy (Jaasma \& Koper, 1999; Moore \& Masterson, 1996; Wilson et al., 1974). When students perceive that their teachers are available and approachable, they tend to feel motivated and engaged with a particular subject (Mazer, 2013; Rocca, 2009). Considering the relevance that the affective dimension has for the quality of interactions, teachers' positive disposition to interact can be an important strategy 
to show closeness and care in and outside classes. It can encourage building interactions based on trust where teachers show approachability and interest on students' learning, and students feel supported and close to their teachers.

\subsection{Academic Benefits of Positive Teacher-Student Interactions}

This study shows that positive teacher-student interactions benefit students' motivation, engagement and learning in the first year of university. First, there is an association between having caring, close and supportive teacher-student interactions and students' motivation with their studies. These positive interactions help students to feel supported and confident in their abilities and knowledge. These experiences of support and confidence are related to two key components that promote students' intrinsic motivation (Ryan \& Deci, 2000).

According to Ryan and Deci (2000), in the educational context, teachers who promote recurrent experiences of competence, autonomy and relatedness encourage students' intrinsic motivation that benefits their learning. Findings of the present study suggest that experiences of confidence and relatedness or being supported can promote students' motivation in the first year. These results coincide with other studies that evaluated the experiences of the first year undergraduate students. For instance, Komarraju et al. (2010) and Trolian, Jach, Hanson, and Pascarella (2016) indicate that high-quality teacher-student interactions were positively associated with students' motivation.

Why do positive teacher and student interactions facilitate students' motivation? One possible explanation is related to the characteristics of these interactions in the first year. Caring and supportive teacher-student interactions facilitate students' learning and personal growth. In fact, when teachers understand students' needs, show interest for their learning, and give thoughtful answers, students feel supported, confident and interested in studying and achieving their learning objectives. Because students can understand the content and the relevance of it for the subject, they are more likely to feel confident and motivated in a subject. For example, Komarraju et al. (2010) found that students who perceived their teachers as approachable and had respectful interactions with them, felt interested and motivated with the subject. Also, Trolian et al. (2016) report that teachers' interest for personal growth and learning was considered a predictor for academic motivation in undergraduate students. The emotional and supportive aspects of positive teacher-student 
interactions contribute to the understanding of the association between interactions and motivation in the first year of university.

Second, positive teacher and student interactions can influence students' engagement. Having positive interactions with teachers can encourage students to spend time and energy on academic activities. According to Astin (1999), students' physical and psychological dedication on educational activities indicates their engagement in the educational experience that can have a positive impact on other academic processes. In fact, Groves et al. (2015) and Richardson and Radloff (2014) suggest that students' engagement is related to satisfaction with the educational experience, motivation, learning and retention. The findings of the current research suggest that promoting positive teacher and student interactions in the first year can make a real difference in students' levels of satisfaction with the educational experience and engagement with their studies.

Perhaps, teachers' engagement in students' learning can help to understand the association between teacher-student interactions and students' engagement. In fact, when teachers dedicate time, consider students' needs and give useful answers to inquiries promote their engagement in a particular subject. Based on the finding of their study, Groves et al. (2015) indicate that the amount of effort that teachers put in the interactions facilitating students' learning was related to the amount of effort that students would spend in their learning. In the study of Cotten and Wilson (2006) students who perceived teachers' dedication to their learning felt responsible for succeeding and showed to teachers that the help was valuable. It suggests that students are sensible and perceptive to their teachers' dedication influencing their own dedication to academic activities. This argument emphasises the active role that teachers play in the interactions with students to facilitate their academic benefits.

Third, this present research shows that positive teacher-student interactions influence students' learning in the first year. This finding coincides with other studies about the benefits of positive teacher and student interactions for learning, such as survey-based research (Hixenbaugh et al., 2012; Kim \& Lundberg, 2016; Kuh et al., 2010; Lyken-Segoseb, 2015; Pascarella \& Terenzini, 1991), and qualitative studies (Chan et al., 2017). The links between learning, motivation and engagement can explain this finding. For example, Kim and Sax (2014) and Pascarella (1985) affirm that students that have positive and frequent interactions with their teachers are usually more engaged in classrooms. When students are engaged, they tend to challenge themselves and seek help from teachers to meet their educational goals improving their learning and academic performance (Kim \& Sax, 2014). 
The main implication of this is that promoting positive teacher-student interactions in the first year have significant effects on motivation, engagement and learning.

\subsubsection{Positive teacher-student interaction and sense of belonging.}

Positive interactions with teachers can facilitate students' sense of belonging to their classrooms helping them to feel part of their subjects and majors. The relevance of this influence is the association that some studies have found between a sense of belonging to classrooms and motivation and engagement. Freeman et al. (2007) evaluated the feeling of belonging of first year students and reported that students who had frequent and positive interactions with their teachers in classrooms felt that teachers cared about their learning and were more connected to their classes influencing their motivation and engagement. The present research indicates that close, caring and supportive teacher-student interactions encourage students' feelings of belonging and connection to their classes. In these classes, teachers usually promote students' participation facilitating students to feel comfortable and ask questions that benefit their learning.

Additionally, students' sense of belonging to the class also can facilitate their social integration through the interactions with peers. Zumbrunn et al. (2014) reported that students that felt highly connected to their classes also felt that were accepted and supported by their peers. Feeling accepted among the groups of peers is essential for first year students that are adjusting and integrating socially to a particular institution (Tinto, 1993). Then, it is probable that teachers who create a supportive and caring environment in classes not only promote positive interactions with students but also facilitate the interactions among peers, for example, through participation. Having these interactions with peers can smooth the students' transition to the institutions.

Despite the feelings of belonging to their classrooms, first year students think that developing a sense of belonging to the university is not related to the interactions with teachers. This finding is striking because developing a sense of belonging to the university has been considered key to retention and academic performance in the first year (Lizzio, 2006; Pascarella \& Terenzini, 1991; Tinto, 1993). Main transition theories establish that teacher-student interactions influence students' sense of belonging to institutions and faculties having a positive effect on academic persistence (Lizzio, 2006; Pascarella \& Terenzini, 1991; Tinto, 1993). For instance, Lizzio (2006) postulates that through the interactions with students, academic staff teaches values, sets academic expectations and 
explains social conventions of a particular institution. Those values and expectations contribute to the understanding of the student identity of a particular faculty and institution (Lizzio, 2006). Additionally, some studies have affirmed that students' feelings of belonging to the universities also influence students' motivation and engagement (Freeman et al., 2007; Wilson et al., 2015; Zumbrunn et al., 2014).

Two reasons could explain the discrepancy between the findings of the present study and the main arguments of the models of transition. The first one can be the size of the university where participants studied. Similar to the majority of Australian higher education institutions, the university selected for this study has a large cohort of students and staff in undergraduate degrees, especially in the first year. Also, first year students often believe that developing feelings of connection to the university is related to social integration, specifically through meeting staff and peers (Scanlon, Rowling, and Weber, 2007). However, large classes and limited interactions with teachers may impede to meet other classmates and teachers in their first year. Therefore, joining extra-curricular activities can be an effective strategy to facilitate students' social integration to the university. Lizzio (2006) and Tinto (1993) have indicated the relevance to make connections within the faculties or institution in different academic and non-academic activities for developing a sense of connectedness to the institution.

A second explanation is that first year students have only one year or less of experience in their degrees in the university. It is probable that first year students are at the beginning of the identification process with their majors and their adaptation to become a university student (Harvey et al., 2006). Then, a lack of connection to the university can be expected at that stage of students' studies. In fact, the latest results of Students Experience Survey (SES) show that only half of first year students felt connected to the university (Quality Indicators for Learning and Teaching (QILT), 2017c).

The disconnection between developing a sense of belonging to an institution and teacher-student interactions in that institution can reflect students' lack of clarity of the benefits of the interactions. It is probable that first year students are receiving unclear and implicit messages from academic staff about the relevance of interactions. This leads to consider the responsibilities of teachers on that issue. According to Lizzio (2006) and Tinto (1993), teaching staff is responsible for facilitating first year students' sense of belonging to institutions and their academic and social integration, especially by interacting with students. In the Australia context, most of teacher-student interactions occurred in the classrooms. Therefore, higher education coordinators should focus on promoting the benefits of 
interactions in classrooms through giving direct messages to teachers and first year students. Some strategies to deliver these messages are explained in the recommendations section.

In brief, the findings of this research indicate that positive teacher and student interactions in the first year of university benefit students' motivation, engagement, learning and their sense of belonging to classrooms. To illustrate these findings, Figure 5.1 shows a diagram of the links between positive teacher and student interactions and academic influences integrating the effect of sense of belonging to classrooms.

Figure 5.1 Diagram integrative of academic benefits of teacher-student interactions

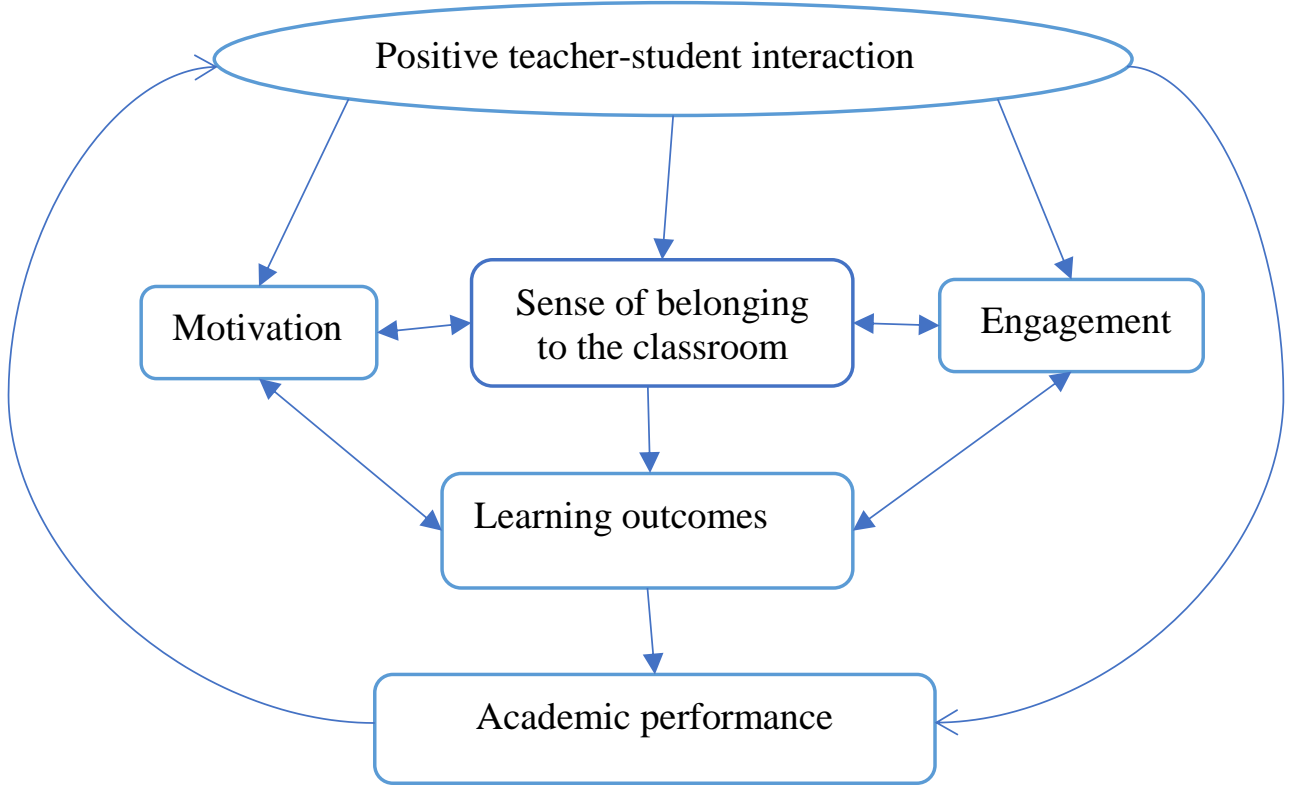

As Figure 5.1 presents, positive teacher and student interactions influence students' motivation, engagement and their sense of belonging to a particular class. These three educational benefits can facilitate the achievement of learning outcomes that may reinforce students' motivation and engagement in that subject. Finally, the achievement of learning outcomes can influence students' academic performance that impacts on students' decision to interact recurrently with their teachers.

\subsection{Limitations and Suggestions for Further Research}

This study contributes to the understanding of students' experiences of their interactions with teachers. However, there are some limitations related to the participants and research methods used. This study considered the experiences of a group of undergraduate 
students of one particular institution. Further research should consider other Australian institutions and evaluate the experience of students from diverse fields and academic settings. It could offer a broad perspective on the topic in the Australian context, especially in the first year.

Additionally, the participation of students was voluntary, and that could imply that some of the students' experiences present extreme views on the topic. In other words, participants may have strong positive or negative experiences of the interactions with teachers in the first year and the participation in the study was a way to express their satisfaction or dissatisfaction with the interactions with teachers. Similarly, it is probable that participants were high academic achievers in their degrees having time and interest to report their experiences in their study. Although the views of participants were valuable and unique, they also may reflect a partial vision of the reality. Therefore, the findings should be interpreted carefully considering this limitation.

The current study only used semi-structured interviews as research methods limiting the triangulation of the data from other methods. Therefore, further qualitative studies should apply other research methods, for example, classrooms observations that could complement students' perspectives of teacher-student interactions. In addition, this research evaluated only students' perspectives that contribute to the understanding of one side of the topic. Further studies should consider other data sources, for example, the perspectives of tutors and lecturers that could give valuable insights to comprehend teacher and student interactions in the first year.

Finally, participants were interviewed only once in their semester reporting a retrospective view of their expectations and experiences. As discussed in the literature on teacher and student interactions, building relationships is a process that develops and changes over time. Further research should focus on the development of teacher and student interactions in the first year evaluating several times the participants' perceptions, for example, before students start their degrees, after the first semester and then at the end of the first year. These longitudinal studies could show how interactions with teachers could modify considering the transition of students.

Despite these limitations, this study has provided valuable insights of the experiences of a group of undergraduate students on teacher and student interactions in the first year. Findings of this research show the benefits of positive teacher and student interactions and the relevance to promote these interactions in the first year of university. 


\subsection{Recommendations}

The results of this study suggest the importance of teacher and student interactions for the first year of university. Based on these findings, the researcher suggests two recommendations for higher education institutions and administrators in the areas of first year curriculum and professional development of teachers to encourage positive interactions.

Positive teacher-student interactions are key factors to promote academic adjustment and sense of belonging to the university and school. Therefore, promoting interactions between staff and students should be included in the first year curriculum through first year orientations and programs, disciplinary and core subjects. Using a wide approach in promoting positive interactions can make visible for students the benefits, places and ways in which they can interact with staff. This information can help students to know what expect in the university regarding the interactions. As shown in the present study, correspondence or discrepancy between students' expectations and their actual experiences influences their levels of satisfaction with their educational experience and the adjustment to the university context.

An example of wide-approach curricular interventions in the first year is the work of Sally Kift and the transition pedagogy (Kift, 2008). Transition pedagogy is a framework that suggests institutional and academic strategies to create a supportive university environment for first year students. This model consists of seven principles, Transition, Diversity, Design, Engagement, Assessment, and Evaluation and Mentoring that facilitate students' success, engagement and retention. The principle of Engagement considers the relevance of promoting interactions between students and staff and peers through the use of interactive teaching strategies, for example teamwork and mentoring (Kift, Nelson \& Clarke, 2010).

The findings of the current research also have implications for the professional development of teachers. Teachers play an active role in facilitating the interactions with students. For that reason, it is fundamental that teachers have the necessary skills and knowledge to facilitate interactions with students in the first year. This suggests that universities should design training programs for teachers in the topic that convey the benefits of teacher and student interactions for students' learning in the first year. Training programs should help teachers to be aware of the needs of first year students and their role in facilitating the interactions. Besides, training programs should explain key strategies to promote these interactions in and out of classrooms, for example, techniques to develop the emotional components of the interactions. 
These trainings should be part of any program of professional development for teachers in higher education institutions. However, higher education coordinators and administrators should pay particular attention to beginning teachers who usually start their teaching careers as tutors. The findings of the present research suggest that tutors have more opportunities to interact with students and students expect to build close and frequent interactions with them. In this context, higher education coordinators should support beginning teachers providing training programs on strategies that facilitate positive teacher and student interactions, for example, strategies to show interest and understanding for students learning needs.

\subsection{Conclusion}

This study examined teacher and student interactions in the first year of university from the perspective of a group of undergraduate students. Findings of this research suggest that encouraging positive teacher and student interactions in the first year should be part of the agenda of universities to facilitate the academic and social adjustment of commencing students. 


\section{References}

Astin, A. (1977). Four critical years (1st ed.). San Francisco: Jossey-Bass Publishers.

Astin, A. (1993). What matters in college?: Four critical years revisited (1st ed.). San Francisco, CA: Jossey-Bass.

Astin, A. (1999). Student involvement: A developmental theory for higher education. Journal of College Student Development, 40(5), 518-529. Retrieved from http://search.proquest.com.ezp.lib.unimelb.edu.au/docview/195180247?accountid=12 372

Australian Council for Educational Research (ACER). (2010). Getting first-year students engaged. Retrieved from https://www.acer.edu.au/files/AUSSE_Research_ Briefing_Vol6.pdf

Australian Council for Educational Research (ACER). (2016). Australian survey of student engagement. Retrieved from https://www.acer.edu.au/ausse

Australian Council for Educational Research (ACER). (2017a). Student engagement questionnaire. Retrieved from https://www.acer.edu.au/files/AUSSE_2011_SEQ.pdf

Australian Council for Educational Research (ACER). (2017b). Student engagement briefing 2012 AUSSE survey Australasia university. Retrieved from https://www.acer.org/files/AUSSE_2012_Australasia_University_Engagement_Briefi ng.pdf

Australian Government Department of Education and Training. (2014). 2013 Appendix 4 Attrition, success and retention. Retrieved from https://docs.education.gov.au/ node $/ 35983$

Australian Qualifications Framework Council. (2013). Australian qualifications framework. Retrieved from https://www.aqf.edu.au/sites/aqf/files/aqf-2nd-edition-january2013.pdf

Baik, C., Naylor, R., \& Arkoudis, S. (2015). The first year experience in Australian universities: Findings from two decades, 1994-2014. Melbourne, Australia: Centre for the Study of Higher Education, The University of Melbourne.

Beattie, I. R., \& Thiele, M. (2016). Connecting in class? College class size and inequality in academic social capital. Journal of Higher Education, 87(3), 332-362. doi:10.1353/jhe.2016.0017

Boyatzis, R. E. (1998). Transforming qualitative information: Thematic analysis and code development. Thousand Oaks, CA: Sage. 
Bowden, J. L.-H. (2013). What's in a relationship? Asia Pacific Journal of Marketing and Logistics, 25(3), 428-451. Retrieved from http://search.proquest.com.ezp.lib.unimelb. edu.au/docview/1370335810?accountid=12372

Braun, V., \& Clarke, V. (2006). Using thematic analysis in psychology. Qualitative Research in Psychology, 3(2), 77-101. doi:10.1191/1478088706qp063oa

Braun, V., \& Clarke, V. (2013). Successful qualitative research: A practical guide for beginners. London, England: Sage.

Brinkworth, R., McCann, B., Matthews, C., \& Nordstrom, K. (2009). First year expectations and experiences: Student and teacher perspectives. Higher Education, 58(2), 157-173. doi:10.1007/s10734-008-9188-3

Chan, Z. C. Y., Tong, C. W., \& Henderson, S. (2017). Uncovering nursing students' views of their relationship with educators in a university context: A descriptive qualitative study. Nurse Education Today, 49, 110-114. doi:10.1016/j.nedt.2016.11.020

Chickering, A., \& Gamson, Z. (1991). Appendix A: Seven principles for good practice in undergraduate education. New Directions for Teaching and Learning, 1991(47), 6369. doi:10.1002/t1.37219914708

Christie, H., Tett, L., Cree, V., \& McCune, V. (2016). 'It all just clicked': A longitudinal perspective on transitions within university. Studies in Higher Education, 41(3), 478490. doi:10.1080/03075079.2014.942271

Cokley, K., Komarraju, M., Patel, N., Castillon, J., Rosales, R., Pickett, R., . . Pang, L.-S. (2004). Construction and initial validation of the student-professor interaction scale. College Student Affairs Journal, 24(1), 32-50. Retrieved from http://www.eric.ed.gov/ contentdelivery/ servlet/ERICServlet?accno=EJ956992

Cole, D. (2007). Do interracial interactions matter? An examination of student-faculty contact and intellectual self-concept. Journal of Higher Education, 78(3), 249-281. Retrieved from http:// www.jstor.org/stable/4501210

Cotten, S. R., \& Wilson, B. (2006). Student-faculty interactions: Dynamics and determinants. Higher Education, 51(4), 487-519. doi:10.1007/s10734-004-1705-4

Cox, B. (2011). A developmental typology of faculty-student interaction outside the classroom. New Directions for Institutional Research, 2011(1), 49-66. doi:10.1002/ir.416

Cox, B., \& Orehovec, E. (2007). Faculty-student interaction outside the classroom: A typology from a residential college. Review of Higher Education, 30(4), 343-362. doi:10.1353/rhe.2007.0033 
Cox, M., Zhu, J., Cekic, O., Chavela, R., \& London, J. (2010). Knowledge or feelings: Firstyear students' perceptions of graduate teaching assistants in engineering. The Journal of Faculty Development, 24(1), 27-34. Retrieved from http://search.proquest. com.ezp.lib.unimelb.edu.au/docview/868918569?accountid=12372

Creswell, J. W. (2014). Research design: Qualitative, quantitative, and mixed method approaches (4th ed.). Thousand Oaks, CA: Sage.

Delaney, A. M. (2008). Why faculty-student interaction matters in the first year experience. Tertiary Education \& Management, 14(3), 227-241. doi:10.1080/13583 880802228224

Dobransky, N. D., \& Frymier, A. B. (2004). Developing teacher-student relationships through out of class communication. Communication Quarterly, 52(3), 211-223. doi:10.1080/01463370409370193

Fassinger, P. A. (1995). Understanding classroom interaction: Students' and professors' contributions to students' silence. Journal of Higher Education, 66(1), 82-96. doi:10.2307/2943952

Feldman, R. S. (1983). Personality factors and expectation effects in teacher-student interaction. Paper presented at the Ninety-first Annual Convention of the American Psychological Association, Anaheim, CA. http://files.eric.ed.gov/fulltext/ ED239184.pdf

Fleischman, D., \& Imaz-Marial, O. (2015). Going “old school”: From bedside manner to deskside manner. Student Success, 6(2), 81-86. Retrieved from https://studentsuccessjournal.org/article/download/287/297.

Freeman, T. M., Anderman, L. H., \& Jensen, J. M. (2007). Sense of belonging in college freshmen at the classroom and campus levels. Journal of Experimental Education, 75(3), 203-220. Retrieved from http://www.jstor.org.ezp.lib.unimelb.edu.au/ stable/20157456

Fuentes, M. V., Ruiz Alvarado, A., Berdan, J., \& DeAngelo, L. (2014). Mentorship matters: Does early faculty contact lead to quality faculty interaction? Research in Higher Education, 55(3), 288-307. doi: 10.1007/s11162-013-9307-6

Gibney, A., Moore, N., Murphy, F., \& O'Sullivan, S. (2011). The first semester of university life; 'Will I be able to manage it at all?'. Higher Education, 62(3), 351-366. doi:10.1007/s10734-010-9392-9

Good, J., Colthorpe, K., Zimbardi, K., \& Kafer, G. (2015). The roles of mentoring and motivation in student teaching assistant interactions and in improving experience in 
first-year biology laboratory classes. Journal of College Science Teaching, 44(4), 8898. Retrieved from http://www.jstor.org.ezp.lib. unimelb.edu.au/stable/43631870

Grantham, A., Robinson, E. E., \& Chapman, D. (2015). "That truly meant a lot to me": A qualitative examination of meaningful faculty-student interactions. College Teaching, 63(3), 125-132. doi:10.1080/87567555.2014.985285

Groves, M., Sellars, C., Smith, J., \& Barber, A. (2015). Factors affecting student engagement: A case study examining two cohorts of students attending a post-1992 university in the United Kingdom. International Journal of Higher Education, 4(2), 27-37. Retrieved from http://www.eric.ed.gov/ contentdelivery/servlet/ERICServlet? accno $=\mathrm{EJ} 1060577$

Hagenauer, G., \& Volet, S. E. (2014). Teacher-student relationship at university: An important yet under-researched field. Oxford Review of Education, 40(3), 370-388. doi:10.1080/03054985.2 014.921613

Harvey, L., Drew, S., \& Smith, M. (2006). The first-year experience: A review of literature for the Higher Education Academy Retrieved from https://www.heacademy.ac. uk/knowledge-hub/first-year-experience-literature-review-executive-summary

Hausmann, L. R. M., Schofield, J. W., \& Woods, R. L. (2007). Sense of belonging as a predictor of intentions to persist among African American and White first-year college students. Research in Higher Education, 48(7), 803-839. doi:10.1007/s11162007-9052-9

Hixenbaugh, P., Dewart, H., \& Towell, T. (2012). What enables students to succeed? An investigation of socio-demographic, health and student experience variables. Psychodynamic Practice, 18(3), 285-301. doi:10.1080/14753634.2012.695887

Hurtado, S., \& Carter, D. (1997). Effects of college transition and perceptions of the campus racial climate on Latino students' sense of belonging. Sociology of Education, 70(4), 324-345. doi: $10.2307 / 2673270$

Hurtado, S., Eagan, M. K., Tran, M. C., Newman, C. B., Chang, M. J., \& Velasco, P. (2011). 'We do science here': Underrepresented students' interactions with faculty in different college contexts. Journal of Social Issues, 67(3), 553-579. doi:10.1111/j.15404560.2011.01714.x

Jaasma, M. A., \& Koper, R. J. (1999). The relationship of student-faculty out-of-class communication to instructor immediacy and trust and to student motivation. Communication Education, 48(1), 41-47. doi:10.1080/03634529909379151 
Kift, S. M. (2008, June). The next, great first year challenge: Sustaining, coordinating and embedding coherent institution-wide approaches to enact the FYE as "everybody's business". Paper pesented at the 11th International Pacific Rim First Year in Higher Education Conference, Hobart, Australia. Retreived from http://fyhe.com.au/past_papers/papers08/presentation\%20files/FYHE\%20Keynote\%2 0-\%20Kift.pdf

Kift, S. M., Nelson, K. J., \& Clarke, J. A. (2010). Transition pedagogy: A third generation approach to FYE: a case study of policy and practice for the higher education sector. The International Journal of the First Year in Higher Education, 1(1), 1-20. Retrieved from https://eprints.qut.edu.au/33635/1/c33635.pdf

Kim, Y. K., \& Lundberg, C. A. (2016). A structural model of the relationship between student-faculty interaction and cognitive skills development among college students. Research in Higher Education, 57(3), 288-309. doi:10.1007/s11162-015-9387-6

Kim, Y. K., \& Sax, L. J. (2014). The effects of student-faculty interaction on academic selfconcept: Does academic major matter? Research in Higher Education, 55(8), 780809. doi:10.1007/s11162-014-9335-x

Komarraju, M., Musulkin, S., \& Bhattacharya, G. (2010). Role of student-faculty interactions in developing college students' academic self-concept, motivation, and achievement. Journal of College Student Development, 51(3), 332-342. doi:10.1353/csd.0.0137

Kuh, G. D., \& Hu, S. (2001). The effects of student-faculty interaction in the 1990s. Review of Higher Education, 24(3), 309-332. doi:10.1353/rhe.2001.0005

Kuh, G. D., Jillian, K., Schuh, J., \& Whitt, E. J. (2010). Student success in college: Creating conditions that matter (1st ed.). San Francisco, CA: Jossey-Bass.

Larkin, K., Rowan, L., Garrick, B., \& Beavis, C. (2016). Student perspectives on first year experience initiatives designed for pre-service teachers in their first weeks of university study. Journal of University Teaching and Learning Practice, 13(1), 1-14. Retrieved from http:// www.eric.ed.gov/contentdelivery/servlet/ERICServlet? accno=EJ1097260

Lizzio, A. (2006). Designing an orientation and transition strategy for commencing students: Applying the five senses model. Retrieved from http://fyhe.com.au/wpcontent/uploads/2012/10/Lizzio-TheFivesensesofStudentSuccessSelfAssessmentFrameworkforplanningandreviewofOT_doc.pdf 
Lundberg, C. A. (2014). Peers and faculty as predictors of learning for community college students. Community College Review, 42(2), 79-98. doi:10.1177/0091552113517931

Lyken-Segoseb, D. (2015). Faculty interaction with higher education's "overlooked majority": Investigating the impact of non-classroom interaction on college outcomes for commuter students. (Doctoral dissertation). Available from ProQuest Dissertations \& Theses Global database. (1694548132)

Mazer, J. P. (2013). Student emotional and cognitive interest as mediators of teacher communication behaviors and student engagement: An examination of direct and interaction effects. Communication Education, 62(3), 253-277. doi:10.1080/03634523.2013.777752

Minichiello, V., Aroni, R., \& Hays, T. N. (2008). In-depth interviewing: Principles, techniques, analysis (3rd ed.). Sydney, Australia: Pearson Education Australia.

Moore, A., \& Masterson, J. T. (1996). College teacher immediacy and student ratings of instruction. Communication 29-39. doi:10.1080/03634529609379030

Morieson, L., Carlin, D., Clarke, B., Lukas, K., \& Wilson, R. (2013). Belonging in education: Lessons from the belonging project. The International Journal of the First Year in Higher Education, 4(2), 87-96. Retrieved from http://go.galegroup.com.ezp.lib .unimelb.edu.au/ps/i.do?ty=as \&v=2.1\&u=unimelb\&it=DIourl\&s=RELEVANCE\&p= AONE\&qt=SN 1838-2959 VO 4 SP 87 IU 2\&lm=DA 120130000 $\& \mathrm{sw}=\mathrm{w} \&$ authCount $=1$

Organization for Economic Co-operation and Development (OECD). (2016). Education at a Glance 2016: OECD Indicators. Australia. doi:10.1787/eag-2016-41-en

Pascarella, E. T. (1980). Student-faculty informal contact and college outcomes. Review of Educational Research, 50(4), 545-595. Retrieved from http://www.jstor.org.ezp.lib.unimelb.edu. au/stable/1170295

Pascarella, E. T. (1985). College environmental influences on learning and cognitive development: A critical review and synthesis. In J. C. Smart (Ed.), Higher education: Handbook of theory and research (Vol. 1, pp. 1-61). New York, NY: Agathon Press.

Pascarella, E. T., \& Terenzini, P. T. (1991). How college affects students: Findings and insights from twenty years of research (1st ed.). San Francisco, CA: Jossey-Bass.

Patton, M. Q. (2002). Qualitative research \& evaluation methods (3rd ed.). Thousand Oaks, CA: Sage. 
Pianta, R. C. (1999). Enhancing relationships between children and teachers. doi:10.1037/10314-000

Pianta, R. C., Hamre, B. K., \& Mintz, S. (2012). Classroom assessment scoring system: Secondary manual. Charlottesville, VA: Teachstone.

Quality Indicators for Learning and Teaching (QILT). (n.d.) Student experience. Retrieved from https://www.qilt.edu.au/about-this-site/student-experience

Quality Indicators for Learning and Teaching (QILT). (2017a). 2016 Student Experience Survey. Retrieved from https://www.qilt.edu.au/docs/default-source/gosreports/2017/2016-ses-national-report final.pdf?sfvrsn=14e0e33c_5

Quality Indicators for Learning and Teaching (QILT). (2017b). The University of Melbourne-Student experience-undergraduate. Retrieved from https://www.qilt.edu.au/institutions/list/institution/the-university-of-melbourne

Quality Indicators for Learning and Teaching (QILT). (2017c). 2016 SES report tables. Retrieved from https://www.qilt.edu.au/about-this-site/student-experience

Retna, K. S., Chong, E., \& Cavana, R. Y. (2009). Tutors and tutorials: Students' perceptions in a New Zealand university. Journal of Higher Education Policy and Management, 31(3), 251-260. doi:10.1080/13600800902974336

Richardson, S., \& Radloff, A. (2014). Allies in learning: Critical insights into the importance of staff-student interactions in university education. Teaching in Higher Education, 19(6), 603-615. doi:10.1080/13562517.2014.901960

Rocca, K. A. (2009). Participation in the college classroom: The impact of instructor immediacy and verbal aggression. Journal of Classroom Interaction, 43(2), 22-33. Retrieved from http://www.jstor.org/ stable/23869675

Rugutt, J., \& Chemosit, C. C. (2009). What motivates students to learn? Contribution of student-to-student relations, student-faculty interaction and critical thinking skills. Educational Research Quarterly, 32(3), 16-28. Retrieved from http://search.proquest.com.ezp.lib.unimelb.edu.au/docview/216207853?accountid=12 372

Ryan, R. M., \& Deci, E. L. (2000). Self-determination theory and the facilitation of intrinsic motivation, social development, and well-being. The American Psychologist, 55(1), 68-78. Retrieved from http://ovidsp.tx.ovid.com.ezp.lib.unimelb.edu.au/ sp3.25.0a/ovidweb.cgi?\&S=DLBLFPLELJDDCKGLNCGKNCLBDNEBAA00\&Lin $\mathrm{k}+$ Set $=$ S.sh.22.23.27.31\%7c7\%7csl_10 
Scanlon, L., Rowling, L., \& Weber, Z. (2007). 'You don't have like an identity ... you are just lost in a crowd': Forming a student identity in the first-year transition to university. Journal of Youth Studies, 10(2), 223-241. doi:10.1080/13676260600983684

Schreier, M. (2013). Qualitative content analysis. In U. Flick (Ed.), The SAGE handbook of qualitative data analysis (pp. 170-183). doi:10.4135/9781446282243

Sevinç, S., \& Gizir, C. A. (2014). Factors negatively affecting university adjustment from the views of first-year university students: The case of Mersin University. Educational Sciences: Theory and Practice, 14(4), 1301-1308. Retrieved from http://search.proquest.com.ezp.lib.unimelb.edu.au/docview/1619570908? accountid $=12372$

Teichler, U. (1998). Massification: A challenge for institutions of higher education. Tertiary Education and Management, 4(1), 17-27. doi:10.1080/13583883.1998.9966942

Tinto, V. (1993). Leaving college: Rethinking the causes and cures of student attrition (2nd ed.). Chicago, IL: University of Chicago Press.

Trolian, T. L., Jach, E. A., Hanson, J. M., \& Pascarella, E. T. (2016). Influencing academic motivation: The effects of student-faculty interaction. Journal of College Student Development, 57(7), 810-826. doi:10.1353/csd.2016.0080

Turner, P., \& Thompson, E. (2014). College retention initiatives meeting the needs of millennial freshman students. College Student Journal, 48(1), 94-104. Retrieved from https://web-a-ebscohoscom.ezp.lib.unimelb.edu.au/ehost/pdfviewer/pdfviewer? vid=1\&sid=8b43f430-8573-43b2-af09-8612adc46445\%40sessionmgr4006

Walsh, C., Larsen, C., \& Parry, D. (2009). Academic tutors at the frontline of student support in a cohort of students succeeding in higher education. Educational Studies, 35(4), 405-424. doi:10.1080/03055690902876438

Weaver, R., \& Qi, J. (2005). Classroom organization and participation: College students' perceptions. The Journal of Higher Education, 76(5), 570-601. Retrieved from http//www.jstor.org.ezp.lib.unimelb. edu.au/stable/3838840

Wilson, D., Jones, D., Bocell, F., Crawford, J., Kim, M. J., Veilleux, N., . . Plett, M. (2015). Belonging and academic engagement among undergraduate STEM students: A multiinstitutional study. Research in Higher Education, 56(7), 750-776. doi:10.1007/s11162-015-9367-x 
Wilson, R., Woods, L., \& Gaff, J. (1974). Social-psychological accessibility and facultystudent interaction beyond the classroom. Sociology of Education, 47(1), 74-92. doi: $10.2307 / 2112167$

Wirt, L. G., \& Jaeger, A. J. (2014). Seeking to understand faculty-student interaction at community colleges. Community College Journal of Research and Practice, 38(11), 980-994. doi:10.1080/10668926.2012.725388

Yin, R. K. (2010). Qualitative research from start to finish (1st ed.). New York, NY: Guilford.

Zhang, Z., Hu, W., \& McNamara, O. (2015). Undergraduate student engagement at a Chinese university: A case study. Educational Assessment, Evaluation and Accountability, 27(2), 105-127. doi:10.1007/s11092-015-9213-x

Zumbrunn, S., McKim, C., Buhs, E., \& Hawley, L. R. (2014). Support, belonging, motivation, and engagement in the college classroom: A mixed method study. Instructional Science, 42(5), 661-684. doi:10.1007/s11251-014-9310-0 
Appendices 


\section{Appendix 1: Questions of Semi-Structured Interviews}

\begin{tabular}{|c|c|}
\hline Topic & Questions \\
\hline \multicolumn{2}{|c|}{$\begin{array}{l}\text { RQ 1. What are the expectations and experiences of undergraduate students regarding the interactions } \\
\text { with their tutors and lecturers in the first year of university? }\end{array}$} \\
\hline Expectations & $\begin{array}{l}\text { Thinking back to when you started at the university, What were your } \\
\text { expectations about the interactions with lecturers and tutors? } \\
\text { How much interaction did you expect to have with them? }\end{array}$ \\
\hline Experiences & $\begin{array}{l}\text { What kind of interactions have you had in your course so far? } \\
\text { Did these interactions meet your expectations? How? }\end{array}$ \\
\hline $\begin{array}{l}\text { Rating of experiences } \\
\text { (Quality of interactions) }\end{array}$ & $\begin{array}{l}\text { Rate the experiences of interactions that you had on a scale of } 1 \text { to } 5 \text {, } \\
\text { with } 1 \text { being really negative and unhelpful to } 5 \text { being really positive } \\
\text { and helpful. } \\
\text { What are the characteristics of positive interactions? } \\
\text { What are the characteristics of negative interactions? }\end{array}$ \\
\hline
\end{tabular}

RQ 2. How have these interactions influenced students' motivation, engagement, learning, and sense of belonging to their university?

Influences of interactions What kinds of interactions with teachers help you:

For learning the subject?

To feel motivated to study?

To feel more confident in your ability to do well in your course?

To feel connected with your class?

To feel more connected or like you belong in the university?

How have these interactions helped you with that? 


\section{Appendix 2: Study's Plain Language Statement}

\section{PLAIN LANGUAGE STATEMENT}

Centre for the Study of Higher Education, Melbourne Graduate School of Education

Project: "Teacher and student interactions in the first year of university."

\section{Introduction}

Thank you for your interest in participating in this research project. This page will provide you with further information about the project so that you can decide if you would like to take part in this research.

Please take the time to read this information carefully. You may ask questions about anything you don't understand or want to know more about.

\section{What is this research about?}

The aim of this study is to investigate first-year students' experiences of interactions with university teachers (lecturers and tutors) and the influences of these on their motivation and engagement in learning, as well as their sense of belonging to the university.

\section{What will I be asked to do?}

Should you agree to participate, you would be asked to participate in an interview, so that we can get a more detailed picture of the characteristics of the interactions between teachers and students. With your permission, the interview would be audio-recorded so that we can ensure that we make an accurate record of what you say. We estimate that the total time commitment required of you would not exceed 60 minutes.

\section{What are the possible benefits?}

The findings of this study will not have direct benefits for you. However, the information that you provide can support changes in teaching strategies that will benefit future university students. You will be reimbursed for your time participating in this study coffee vouchers.

\section{How will my confidentiality be protected?}

We intend to protect your anonymity and the confidentiality of your responses to the fullest possible extent, within the limits of the law. Your name and contact details will be kept in a separate, password-protected computer file from any data that you supply. Only the researchers will be able to link your name and data. In the final report, you will be referred to by a pseudonym. We will remove any references to personal information that might allow someone to guess your identity. The data will be used only for this study and kept securely in 
the Centre for the Study of Higher Education five years from the date of publication, before being destroyed.

\section{How will I receive feedback?}

Once the thesis arising from this research has been completed, a summary of the findings will be sent to the email address that you write in the consent form. It is also possible that the results will be presented at academic conferences and published in a journal.

\section{Will participation prejudice me in any way?}

Please be advised that your participation in this study is voluntary. Should you wish to withdraw at any stage, or to withdraw any unprocessed data you have supplied, you are free to do so without prejudice.

\section{Where can I get further information?}

Should you require any further information, or have any concerns, please do not hesitate to contact the researchers on the numbers below.

\section{How do I agree to participate?}

The participation is voluntary. If you would like to participate, please indicate that you have read and understood this information by signing the accompanying consent form and returning it to the researcher Claudia Rivera.

\section{Who can I contact if I have any concerns about the project?}

This research project has been approved by the Human Research Ethics Committee of The University of Melbourne. If you have any concerns or complaints about the conduct of this research project, which you do not wish to discuss with the research team, you should contact the Manager, Human Research Ethics, Office for Research Ethics and Integrity, University of Melbourne, VIC 3010. Tel: +61 383442073 or Email: HumanEthicscomplaints@unimelb.edu.au. All complaints will be treated confidentially. In any correspondence, please provide the name of the research team or the name or ethics ID number of the research project.

Dr. Chi Baik (Supervisor)

ph. 83444212

email: cbaik@unimelb.edu.au

\author{
Ms. Claudia Rivera (Masters' Student) \\ ph: 83444000 \\ email: riverac@student.unimelb.edu.a
}




\section{Appendix 3: Study's Informed Consent}

\section{CONSENT FORM}

Centre for the Study of Higher Education

Melbourne Graduate School of Education

PROJECT TITLE: Teacher and student interactions in the first year of university

Name of participant:

Email:

Name of Investigator(s): Claudia Rivera, Dr Chi Baik, Dr Jason Lodge

1. I consent to participate in this project, the details of which have been explained to me, and I have been provided with a written plain language statement to keep.

2. I understand that the purpose of this research is to investigate the experiences and expectations of first-year students of the interactions with teachers in the university.

3. I acknowledge that:

(a) the possible effects of participating in this project have been explained to me to my satisfaction;

(b) I have been informed that I am free to withdraw from the project at any time without explanation or prejudice and to withdraw any unprocessed data previously supplied;

(c) the project is for research purposes only;

(d) I have been informed that the confidentiality of the information I provide will be safeguarded subject to any legal requirements;

(e) the interview will be audio-recorded;

(f) the participants will be referred by a pseudonym in transcriptions and any publications arising from the research.

(g) after I sign and return this consent form, it will be retained by the researcher. 


\section{Appendix 4: Socio-Demographic Questionnaire}

Name:

1. Sex:

Male Female Other

2. Age: if you are under 18, you cannot participate of the study.

3. Are you an international student?

Yes No

4. If yes, where do you come from?

5.Bachelor degree:

6. Is this degree your first tertiary study after school?

Yes No

7. Are you first in your family to study in the university or another tertiary institution?

Yes No

8. In your current subjects:

How many tutorials do you have per week?

How many labs do you have per week?

How many lectures do you have per week?

Thank you! 


\section{Appendix 5: Example of Coding, Subtopics and Topics}

This table shows an example of coding, subtopic and topic related to the negative characteristics of the quality of interactions reported by one participant.

\begin{tabular}{|c|c|c|c|c|c|c|}
\hline Interview & Participant & Answer & Code & Description & Subtopic & Topic \\
\hline $\mathrm{I} 3$ & BS_1 & $\begin{array}{l}\text { So, I feel } \\
\text { like the } \\
\text { interactions } \\
\text { between } \\
\text { lecturer and } \\
\text { the student } \\
\text { can be quite } \\
\text { poor } \\
\text { because you } \\
\text { don't really } \\
\text { have that } \\
\text { engagement }\end{array}$ & $\begin{array}{l}\text { No } \\
\text { connection }\end{array}$ & $\begin{array}{l}\text { Interaction } \\
\text { with lecturers }\end{array}$ & $\begin{array}{l}\text { Negative } \\
\text { characteristics }\end{array}$ & $\begin{array}{l}\text { Quality of } \\
\text { interactions }\end{array}$ \\
\hline
\end{tabular}




\section{Appendix 6: Ethics Letter of Approval}

7 October 2016

Dr Chi Baik

Melbourne Graduate School of Education

The University of Melbourne

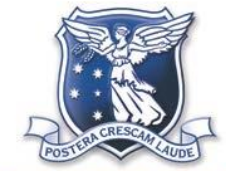

THE UNIVERSITY OF

Dear Dr Baik,

$\overline{M E L B O U R N E}$

I am pleased to advise that the Melbourne Graduate School of Education Human Ethics Advisory Group (MGSE HEAG) has approved the following Minimal Risk application:

Project title: $\quad$ Teachers and students interactions in the first year of university.

Researchers: $\quad$ Chi Baik, Claudia Rivera-Munroz and Jason Lodge.

Ethics ID/HREC: $\quad 1647683$

MGSE HEAG ID: $\quad 142 / 16$

The project has been approved for the period: 7 October 2016 to 31 December 2016

It is your responsibility to ensure that all people associated with the Project are made aware of what has been approved.

Research projects are normally approved to 31 December of the year of approval. Projects may be renewed yearly for up to a total of five years upon receipt of a satisfactory annual report. If a project is to continue beyond five years, a new application will normally need to be submitted.

Please note that the following conditions apply to your approval. Failure to abide by these conditions may result in suspension or discontinuation of approval and disciplinary action.

(a) Limit of Approval: Approval is limited strictly to the research as submitted in your Project application.

(b) Amendments to Project: Any subsequent variations or modifications you might wish to make to the Project must be notified formally to the Human Ethics Advisory Group for further consideration and approval before the revised Project can commence. If the Human Ethics Advisory Group considers that the proposed amendments are significant, you may be required to submit a new application for approval of the revised Project.

(c) Incidents or adverse effects: Researchers must report immediately to the Advisory Group and the relevant SubCommittee anything which might affect the ethical acceptance of the protocol including adverse effects on participants or unforeseen events that might affect continued ethical acceptability of the Project. Failure to do so may result in suspension or cancellation of approval.

(d) Monitoring: All projects are subject to monitoring at any time by the Human Research Ethics Committee.

(e) Annual Report: Please be aware that the Human Research Ethics Committee requires that researchers submit an annua report on each of their projects at the end of the year, or at the conclusion of a project if it continues for less than this time. Failure to submit an annual report will mean that ethics approval will lapse.

(f) Auditing: All projects may be subject to audit by members of the Sub-Committee.

Please quote the ethics registration number and the name of the Project in any future correspondence.

On behalf of the Ethics Committee, I wish you well in your research.

Yours sincerely

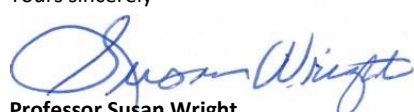

Susan Wright

Deputy Chairperson, Melbourne Graduate School of Education Human Ethics Advisory Group

Phone: 83448339, Email: susan.wright@unimelb.edu.au

cc: Claudia Rivera-Munroz, Jason Lodge and Human Research Ethics Committee (HREC), The Office for Research Ethics and Integrity.

Melbourne Education Research Institute (MERI)

Melbourne Graduate School of Education

Level 9 | 100 Leicester Street | The University of Melbourne Victoria 3010 | Australia

T: +61 383448285 F: +61 383448213 W: www.education.unimelb.edu.au/research 


\section{University Library}

\section{- M I I N E R VA \\ A gateway to Melbourne's research publications}

Minerva Access is the Institutional Repository of The University of Melbourne

Author/s:

Rivera Munoz, Claudia Andrea

Title:

Teacher and student interactions in the first year of university

Date:

2017

Persistent Link:

http://hdl.handle.net/11343/197489

Terms and Conditions:

Terms and Conditions: Copyright in works deposited in Minerva Access is retained by the copyright owner. The work may not be altered without permission from the copyright owner. Readers may only download, print and save electronic copies of whole works for their own personal non-commercial use. Any use that exceeds these limits requires permission from the copyright owner. Attribution is essential when quoting or paraphrasing from these works. 